\title{
Daily synoptic conditions associated with occurrences of compound events in estuaries along North Atlantic coastlines
}

\author{
Paula Camus $^{1}$ (1) | Ivan D. Haigh ${ }^{1}$ | Thomas Wahl ${ }^{2}$ | Ahmed A. Nasr ${ }^{2}$ | \\ Fernando J. Méndez ${ }^{3}$ | Stephen E. Darby ${ }^{4}$ | Robert J. Nicholls ${ }^{5}$
}

${ }^{1}$ School of Ocean and Earth Science, National Oceanography Centre

Southampton, University of Southampton, Southampton, UK

${ }^{2}$ Civil, Environmental, and Construction Engineering \& National Center for Integrated Coastal Research, University of Central Florida, Orlando, Florida, USA

${ }^{3}$ Geomatics and Ocean Engineering Group, Departamento de Ciencias y Técnicas del Agua y del Medio Ambiente, ETSICCP, Universidad de Cantabria, Santander, Spain

${ }^{4}$ School of Geography and Environmental Sciences, University of Southampton, Southampton, UK

${ }^{5}$ Tyndall Centre for Climate Change Research, School of Environmental Sciences, University of East Anglia, Norwich, UK

\section{Correspondence}

Paula Camus, School of Ocean and Earth Science, National Oceanography Centre Southampton, University of Southampton, Waterfront Campus, European Way, Southampton SO14 3ZH, UK.

Email: P.Camus-Brana@soton.ac.uk

\section{Funding information}

US National Science Foundation, Grant/ Award Number: 1929382; UK Natural Environment Research Council, Grant/ Award Number: NE/S010262/1

\begin{abstract}
Coastal compound flooding events occur when extreme events of rainfall, river discharge and sea level coincide and collectively increase water surface elevation, exacerbating flooding. The meteorological conditions that generate these events are usually low-pressure systems that generate high winds and intense rainfall. In this study, we identify the types of synoptic atmospheric conditions that are typically associated with coastal compound events using a weathertype approach, for the North Atlantic coastlines (encompassing northwest Europe and the east coast of the United States). Compound events are identified along the estuaries of the study region from 1980 to 2014 based on an impact function defined by water surface elevation that resulted from the combination of river discharge and sea level. We find that compound events are more frequent along European as opposed to U.S. coastlines. In both cases, they are associated with a few dominant weather patterns. European hotspots of compound events are concentrated in the west coast of United Kingdom, the northwest coast of the Iberian Peninsula and around the Strait of Gibraltar. These areas share the same weather patterns which represent the main pathways of storms that cross the North Atlantic Ocean. In the case of U.S. locations, the areas with highest number of compound events are located mainly in the Gulf of Mexico and along Mexico and along the mid-eastern U.S. coastlines. In these areas, compound events are produced by transitional weather patterns, which describe storms that travel northward parallel to the coastline. Splitting the occurrence of compound events in the corresponding weather types discriminates the interannual variability based on the relationship with dominant climate indices in the North Atlantic Ocean.
\end{abstract}

\section{K E Y W O R D S}

coastal flooding, compound events, estuaries, North Atlantic, weather types 


\section{INTRODUCTION}

The coastal floods experienced along the Atlantic coastlines of North America and Europe often have a compound dimension, where the interaction of multivariate drivers exacerbate the effects. In Hurricane Harvey in 2017, the rainfall in and around Houston would have caused a flood alone, but the impacts were compounded by the slow moving storm surge (Valle-Levinson et al., 2020). Superstorm Sandy in 2012 produced the highest storm surge ever recorded at spring tide and high winds, causing major flood impacts in New York City and surrounding areas, and this was compounded by significant rainfall (Zscheischler et al., 2018). In Brittany, France, 600 persons were affected by coastal flooding in December 2000 that occurred due to the combination of heavy precipitation over several river catchments and a storm surge generated by an extra-tropical storm (HANZE database, Paprotny et al., 2018). Lastly at Lymington, Hampshire on December 24, 1999 the town was flooded due to tidal locking of the high run-off down the Lymington River by a large surge produced by the same storm system, with this flooding overwhelming recently upgraded defences (Ruocco et al., 2011).

These events illustrate clearly that hydrological and oceanographic processes are connected by weather systems. Precipitation extremes can have a wide range of causes, such as convection along orography, thunderstorms, and fronts in addition to cyclones (Messmer and Simmonds, 2021). However, storm surges are driven by barometric pressure effects and strong winds, caused by intense cyclonic activity, which push water towards the coast (Bevacqua et al., 2019). This prerequisite of a cyclonic storm being necessary in the generation of compound flooding events has been confirmed in the comparison of the weather patterns associated with extreme flooding events caused by combinations of storm surges and rainfall along the main U.S. cities (Wahl et al., 2015). This weather prerequisite has also been corroborated in a study performed for the United Kingdom (Hendry et al., 2019) where distinctive differences in storm types experienced along the western and eastern coasts of the United Kingdom explain the relative absence of compound events on the latter as compared to the former. Therefore, an understanding of the underlying phenomena and identification of the drivers of compound events are both important to improve their prediction and risk assessment (Zscheischler et al., 2020).

In the past, composite meteorological maps have been used to examine the synoptic weather systems that most frequently influence co-occurring storm surge and precipitation extremes (Wahl et al., 2015), or skew surge and river discharge extremes (Hendry et al., 2019). A correlation-based, map-typing technique was also applied to identify composite synoptic patterns associated with compound events caused by extreme surges and rainfall (Wu et al., 2018). Methods based on tracking individual cyclones in space and time (i.e., a quasi-Lagrangian approach) were used to identify compound events caused by extreme wind and spatially large precipitation (Messmer and Simmonds, 2021). More sophisticated methods based on dynamical-systems theory have also been applied to co-occurrences of wind and precipitation extremes (De Luca et al., 2020).

Weather types (WTs) provide one of the main methods used to classify atmospheric circulation patterns in synoptic climatology (Yarnal, 1993; Barry and Chorley, 2003). The first synoptic classifications were obtained by applying manual procedures (Hess and Brezowky, 1969; Lamb, 1972) becoming more objective using mainly clustering techniques (Hewitson and Crane, 2002; Sheridan, 2002; Gutiérrez et al., 2005). In addition to being used as a tool for describing atmospheric states and processes, synoptic weather classification has also been used to model the linkage between circulation and surface climate (Huth et al., 2008). This nonlinear relationship between atmospheric conditions (predictor) and the local environmental variables (predictand) has been applied to develop statistical downscaling methods for projecting wave climate (Camus et al., 2014; 2017), an extreme value model (Rueda et al., 2016), or climate emulators for coastal flooding (Anderson et al., 2019; Cagigal et al., 2020). Other applications of synoptic weather patterns analysed climaterelated disasters such as fires (Ruffault et al., 2017) or deep persistence slab avalanches (Schauer et al., 2021).

On the other hand, the definition of compound events has developed from a driver to an impact perspective in recent years. This led Zscheischler et al. (2020) to propose a typology of these events in which flooding is considered to be caused by the interaction between multiple climate drivers and/or hazards within the same geographical region, that may not be extreme themselves, but whereby their joint occurrence causes an extreme impact. The lack of data of the hazard or impact at regional and global scales have resulted in the application of two-sided conditional sampling to bivariate drivers to identify compound flooding potential events (Wahl et al., 2015; Ward et al., 2018; Couasnon et al., 2020; Camus et al., 2021; Nasr et al., 2021). Recently, Eilander et al. (2020) simulated water levels at river mouths generated by the interaction between oceanographic and riverine drivers using a global coupled river-coast flood model framework. This dataset opens the possibility to use water surface elevation as a consistent indicator of flooding hazard. 
Therefore, the overall aim of this study is to relate the spatial and temporal occurrence of compound events along the North Atlantic estuaries to their respective daily weather conditions using (a) a weather-typing approach and (b) the global database of water levels developed by Eilander et al. (2020). Synoptic circulation patterns over more than three decades are obtained by applying classification techniques. The specific objectives are to: (a) improve the understanding of dependence in compound flood-producing extremes identifying the atmospheric patterns that more likely generate these type of events; (b) assess the ability of weather types to capture the spatial and temporal variability of the occurrence of compound flooding potential.

We divide the study area into two sub-domains containing the densely populated European and United States Atlantic coastlines, respectively, thereby capturing systematic differences in the storm activity experienced along both coastlines. Only the extratropical season (December, January, February, March, April and May, DJFMAM) is analysed for the U.S. coastline because tropical cyclones are not properly reproduced in ERAInterim, which is the forcing used for the Eilander et al. (2020) database. These specific features determine two distinct applications of the methodological framework.

The remainder of this paper is structured as follows. Section 2 describes the databases used to define the atmospheric conditions and coastal compound events. The methods applied to identify extreme compound events and classify daily weather conditions are introduced in section 3. Weather patterns in the two subdomains are presented in section 4 . The links between synoptic patterns and the occurrence of compound events are analysed in section 5. Section 6 analyses climate variability and the occurrence of compound events based on their correlation with climate indices. Section 7 provides a discussions and section 8 concludes.

\section{$2 \mid$ DATA}

In this study, we differentiate between the local hydrological and oceanographic variables and the synoptic-scale atmospheric conditions. Local variables are the water surface elevation on the river mouths and the two drivers, sea level and river discharge, that interact and modify water level at the river outlets. The atmospheric conditions are used as large-scale predictors of the local sea-surface dynamics (predictands), and to obtain weather patterns. In addition, several climate indices, representative of the climate variability in the North Atlantic, are used to analyse their influence in the frequency and location of the coastal compound events (CEs).

\section{1 | Local hydrological and oceanographic variables}

\subsection{1 | Water surface elevation}

We use the global database of daily water surface elevations (WSEs) in estuaries (1980-2014), developed by Eilander et al. (2020), that accounts for river dischargestorm surge interactions, to identify the coastal CEs. This dataset is publicly available and contains simulated water levels and discharge at 3,433 river mouth locations globally, including several components of nearshore still water levels. The dataset was generated using a state-ofthe-art global river routing model (CaMa-Flood; Yamazaki et al., 2011), bounded by dynamic sea level. A multimodel ensemble (six members) of global hydrological models and land surface models with meteorological forcing from ERA-Interim (Dee et al., 2011) and MSWEP 27 v1.2 (Beck et al., 2017) were used to force the model CaMa-Flood with runoff data. Only data for catchments with a minimum size of $1,000 \mathrm{~km}^{2}$ are provided here, due to the relatively coarse resolution of the hydrological models.

\subsection{2 | Skew surge}

To characterize the oceanographic flooding driver, storm surge, we used the skew surge parameter $(S)$, which is the difference between the maximum sea level and the maximum astronomical tide within each tidal cycle, regardless of their timing. Daily time series of skew surge are obtained from time series of total water levels which were used to force the hydrodynamic model used by Eilander et al. (2020). Surge levels from the Global Tide and Surge Reanalysis based on the GTSM model (Muis et al., 2016), and tide levels from the FES2012 model (Carrère et al., 2013), defined the dynamic sea level data.

\subsection{3 | River discharge}

Daily time-series of river discharge $(Q)$ were extracted from the CaMa-Flood global model driven with the same precipitation dataset as in Eilander et al. (2020) and forced by a constant mean sea level, which means that the river discharge variable is the result of upstream catchment processes only. For this reason, we use river discharge simulations provided by Couasnon et al. (2020), 
which were generated by routing the mean daily runoff of the JULES model.

\section{2 | Synoptic-scale atmospheric conditions}

River discharge is an integrated result of hydrological processes in a river system in transporting runoff from rain. Therefore, precipitation $(P)$ is considered as the main driver of river discharge, although other climatic and nonclimatic factors affect the fluvial source driver (Bevacqua et al., 2020). However, we only consider atmospheric drivers responsible for the short-term variability (in the order of days). Storm surge is the sea level variation generated by wind and atmospheric pressure changes. Sea level pressure (SLP) represents the geostrophic wind conditions. In order to avoid redundancy of information, only $\mathrm{P}$ and SLP are used in the classification and wind is added to aid understanding of the synoptic conditions.

Hourly SLP, wind and P fields were extracted from the ERA5 reanalysis (Hersbach et al., 2020) at $0.25^{\circ} \times 0.25^{\circ}$ resolution. The ERA5 hourly dataset spans 1979 onwards and is currently publicly available at the Copernicus Climate Change Service. Here, accumulated daily $P$, mean daily SLP, and mean daily wind fields were calculated from hourly data.

\section{3 | Climate indices}

Here we use the North Atlantic Oscillation (NAO) climate index, which was downloaded from the National Oceanic and Atmospheric Administration (NOAA) Climate Prediction Center (www.cpc.ncep.noaa.gov). This leading monthly teleconnection index is derived from rotated empirical orthogonal function (EOF) analysis of the monthly mean standardized 500-mb height anomalies in the Northern Hemisphere, in the region $20^{\circ}-90^{\circ} \mathrm{N}$ (Barnston and Livezey, 1987). We also use the western Europe pressure anomaly (WEPA), a climate index developed by Castelle et al. (2017), and computed as the normalized SLP gradient between Valentia (Ireland) and Santa Cruz de Tenerife (Canary Islands) that best explains winter wave height variability along the Atlantic coast of Europe.

The Pacific-North America (PNA) pattern is one of the dominant modes of low-frequency variability in the Northern Hemisphere extratropics. The PNA index has been chosen as the second mode of a Rotated EOF analysis using monthly mean $500 \mathrm{mb}$ height anomaly data from 1950 over $0-90^{\circ} \mathrm{N}$ latitude.

The El Niño-Southern Oscillation (ENSO) is a periodic fluctuation in sea surface temperature (El Niño) and the air pressure of the overlying atmosphere (Southern Oscillation) across the equatorial Pacific Ocean. The Oceanic Niño Index (ONI) is one of the primary indices, calculated as a 3-month running mean of the sea surface temperature anomalies in an area of the east-central equatorial Pacific Ocean, which is called the Niño3.4 region $(5 \mathrm{~S}-5 \mathrm{~N} ; 170-120 \mathrm{~W})$.

\section{COASTAL COMPOUND EVENTS}

Compound flooding events were defined as extreme WSE events caused by extreme $Q$ and $S$ events. The occurrences of these events were calculated to identify compounddominant locations in the study domain and perform a more detailed analysis in some specific locations (section 5).

\section{1 | Sampling}

A peak over threshold (POT) approach was used to select independent extreme events of WSE, $Q$ and $S$ considering a storm duration of 3 days. A threshold that guarantees three events per year was established. These values were selected following previous studies (e.g., Ward et al., 2018; Bevacqua et al., 2019; Hendry et al., 2019; Eilander et al., 2020; Camus et al., 2021). CEs were defined as those extreme events of WSE that are generated by $Q$ and $S$ over their corresponding POT threshold. The values of $Q$ and $S$ associated with extreme WSE events were selected within a time window of 1 day.

To illustrate the sampling approach, time series of WSE, $Q$ and $S$ during the year when the maximum WSE events occurred at three locations along the European North Atlantic coastlines (see Figure 2 with these locations marked) are shown in Figure 1 (see Figure S1, Supporting Information with the same analysis for the three selected locations along the U.S. coastlines). Some of the selected extreme WSE events are coincident also with the extreme $Q$ and $S$ events selected by POT (represented in black). However, most of the extreme WSE events identified in the second location correspond to extreme $Q$, but not events with $S$ over the POT threshold. These different characteristics of extreme WSE events are reflected in the scatter plots which display the corresponding value of the river discharge and skew surge of these WSE events. The range of the values of WSE, $Q$ and $S$ are different between the different locations. The relationship between these three variables also varies between locations. Spearman correlation coefficients were found to be 0.63 in location 1 and $0.89-0.85$ in locations 2 and 3 for the pair WSE-Q, while they are $0.3,0.26$ and 0.46 at locations 1,2 and 3 , respectively, for WSE-S. 

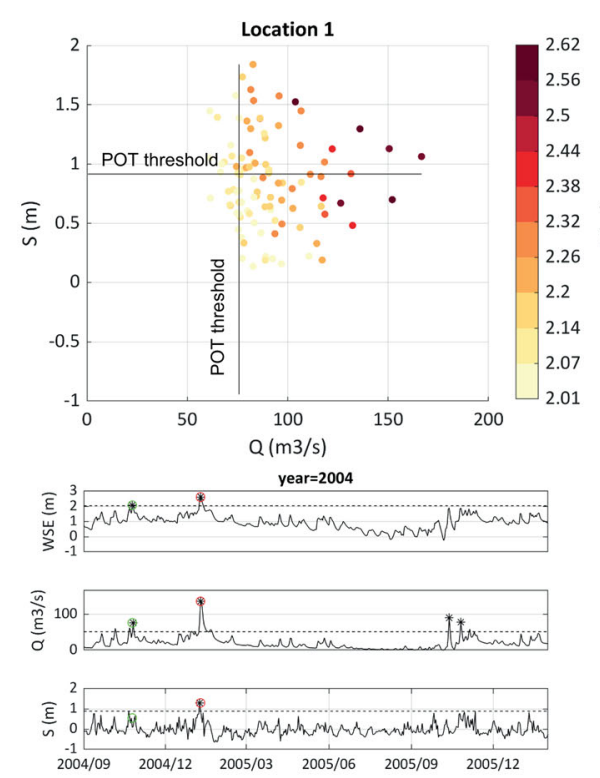
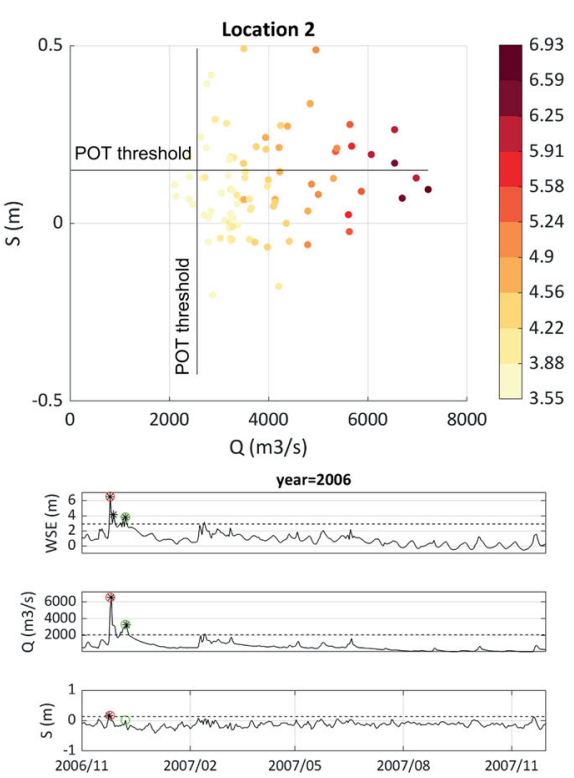
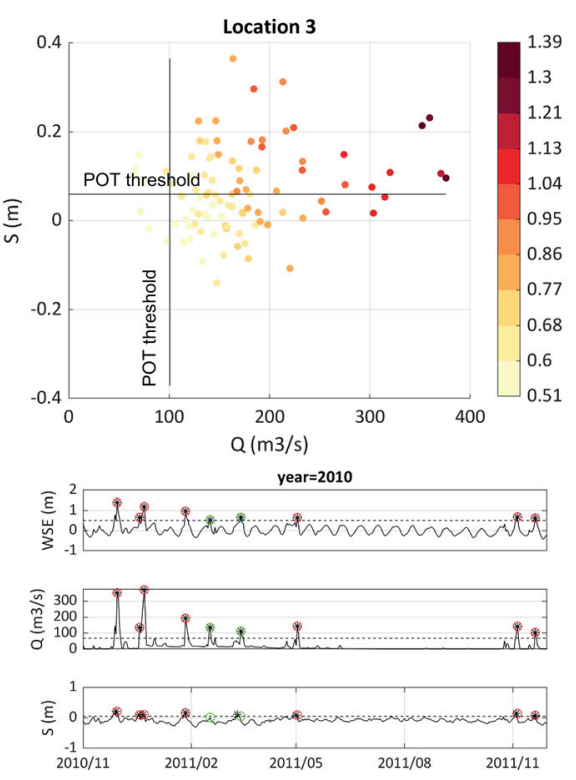

F I G U RE 1 Scatter plots of river discharge ( $Q$ ) against skew surge $(S)$ for the identified extreme water surface elevation (WSE) events (represented by the red scale) at three locations along the European coastline (see Figure 2 for locations). Time series of WSE, $Q$ and $S$ during the year with the highest extreme WSE event. Extreme WSE events which coincide with an extreme $Q$ event are represented with a red circle, those that coincide with an extreme $S$ event are represented with a blue circle, and WSE events that coincide with extreme Q and $\mathrm{S}$ events are represented with a black asterisk [Colour figure can be viewed at wileyonlinelibrary.com]

\section{2 | Identification of compound- dominant locations}

We use the number of CEs as an indicator of compounddominant behaviour. Figure 2 shows these results for the study locations along the European coastlines for the entire year and along the U.S. coastlines only for the extratropical season. Locations with the highest number of CEs (more than 30) are concentrated along the west coast of the United Kingdom, the Iberian Peninsula and the area around the Strait of Gibraltar. Along the U.S. coast, the maximum number of CEs are of the order 20 , and the percentage of locations with this number are much lower than along the European coast. Three compound-dominant locations are selected in each of these two coastlines to perform a detailed analysis of the meteorological conditions that generate these events (section 5).

\section{4 | WEATHER PATTERNS IN THE NORTH ATLANTIC OCEAN}

Weather types (WTs) of the predictor of coastal CEs, defined by SLP and precipitation, were obtained by combining three data mining techniques, following Camus et al. (2014). First, a principal component analysis (PCA) was applied to the multivariate spatial predictor to reduce the data dimensionality and simplify the classification. Second, the predictor in the EOFs space was clustered using k-means algorithm (KMA). Third, the set of clusters was organized in a lattice using a similarity criterion that facilitates understanding a larger number of patterns and discerning transitional nodes between patterns (Sheridan and Lee, 2011).

\section{1 | Predictor definition}

River discharge is directly linked to rainfall intensity over the watershed, as well as being a function of topography, geology and land use. For this reason, we decided to use a dynamic predictor which accounts for precipitation falls during the same day (Day 1) and up to 2 days prior to the occurrence of a compound event simulating the basin time lag. Simultaneously, we introduced information about the evolution of the storm through SLP fields during these 3 days to distinguish between different types of extratropical cyclones. The spatial domain of the predictors for the study sites along European coastlines stretches from latitude $30^{\circ}-70^{\circ} \mathrm{N}$ and from longitude $30^{\circ} \mathrm{W}-10^{\circ} \mathrm{E}$ (European predictor domain). The spatial domain of the predictors for the study sites along U.S. coastlines stretches from latitude $20^{\circ}-55^{\circ} \mathrm{N}$ and from longitude $100^{\circ}-50^{\circ} \mathrm{W}$ (North American predictor domain). 

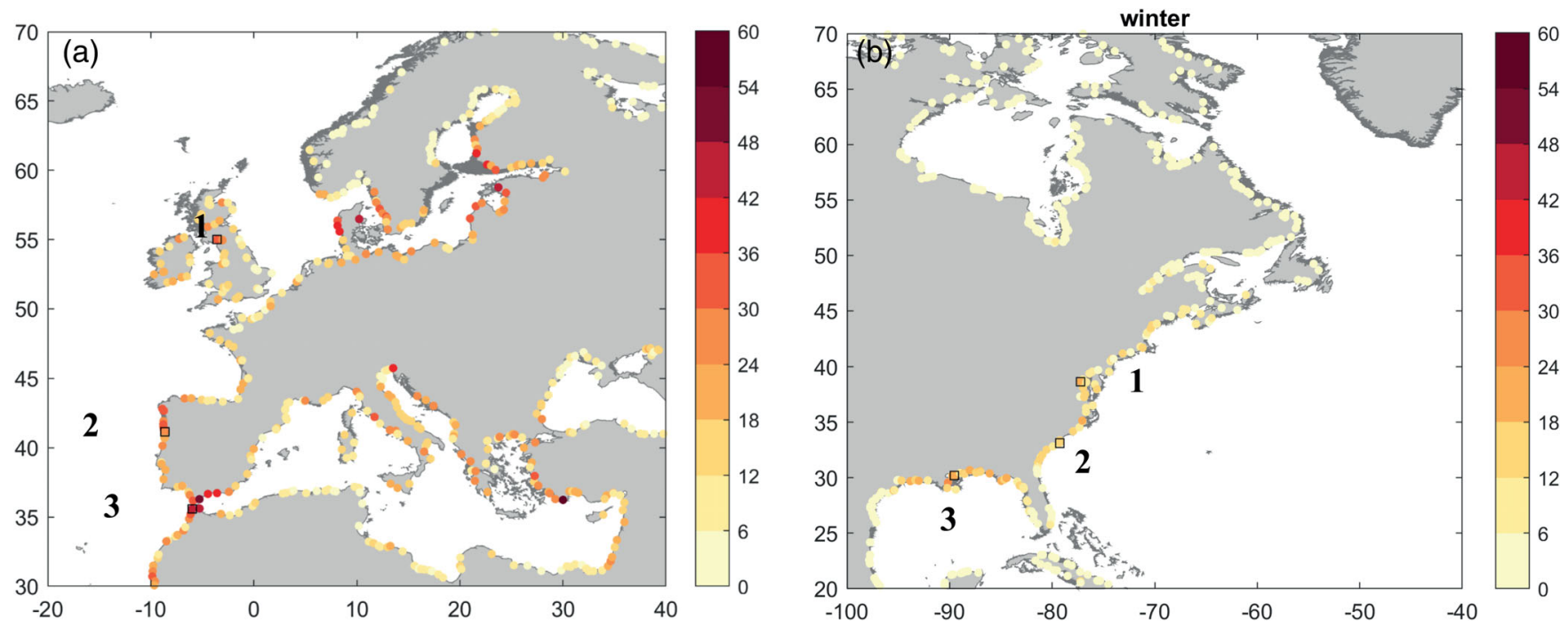

F I G URE 2 (a) Number of coastal compound events (defined as those extreme water surface elevation events generated by the combination of extreme river discharge and skew surge) along the European coastline during the entire year; (b) along the U.S. coastline during the extratropical season (DJFMAM) from 1980 to 2014. Three locations are selected in each of these two coastlines (black squares) for detailed analysis: European coastlines (a): (1) Nith River (Scotland); (2) Douro River (Oporto, Portugal); (3) Oued Tahadart River (Morocco); U.S. coastlines (b): (1) Occuquan River (Belmont Bay, northern Virginia); (2) North Santee River (north Caroline); (3) Pearl River (Mississippi-Louisiana, Gulf of Mexico) [Colour figure can be viewed at wileyonlinelibrary.com]

\section{2 | Synoptic weather types}

Daily dynamic predictors over the European and North American domains were classified into 64 or 49 patterns using KMA, respectively. The number of patterns was based on a compromise between a climatology characterization, but at the same, able to distinguish different lowpressure systems that generate CEs.

\subsection{1 | European subdomain}

Figure 3 shows the 64 WTs that characterized the synoptic patterns for European locations in an organized twodimensional lattice with similar patterns located together, varying smoothly from one cell to another. Only the SLP and P fields corresponding to day 1 are represented. WTs with intense low-pressure systems but different locations of the pressure centre are distributed along the lattice edges. WTs located in the upper right corner of the lattice are characterized by intense low systems over the higher latitudes of the spatial domain, with an important anticyclone over the western Europe. Precipitation is mainly distributed over western part of the Scandinavian Peninsula. WTs located on the left edge of the lattice represent strong low-pressure systems over the north-west domain associated with heavy localized precipitation as the system is displaced to the south. Other relevant WTs which characterize situations of intense low-pressure and precipitation along the western coast of the Iberian Peninsula are located in the lower right corner of the lattice. Figure $3 \mathrm{~b}$ shows the seasonal occurrence probability of the WTs during the historical period (1980-2014), while Figure $3 \mathrm{c}$ is the associated mean duration (in days) of the persistent conditions at each WT. Higher persistence is usually found for the WTs representing anticyclonic conditions, as per the ones located along the upper edge of the lattice.

\subsection{2 | North America subdomain}

The 49 WTs obtained over the North America domain for extratropical season are represented in Figure 4. Four main groups of patterns can be distinguished on the lattice. WTs located on the upper left corner are characterized by large low-pressure systems displaced to the east with precipitation over the ocean. Localized lows over Newfoundland, usually with a dipole structure (i.e., a high-pressure centre over the interior of the North American continent) dominate on the right lower corner. High-pressure systems, some of them with important precipitation over the North Atlantic coastlines, are located in the middle lower cells. On the other hand, local lowpressure systems at different latitudes along the coastline with heavy precipitation are concentrated on the right edge of the lattice. 
(a)

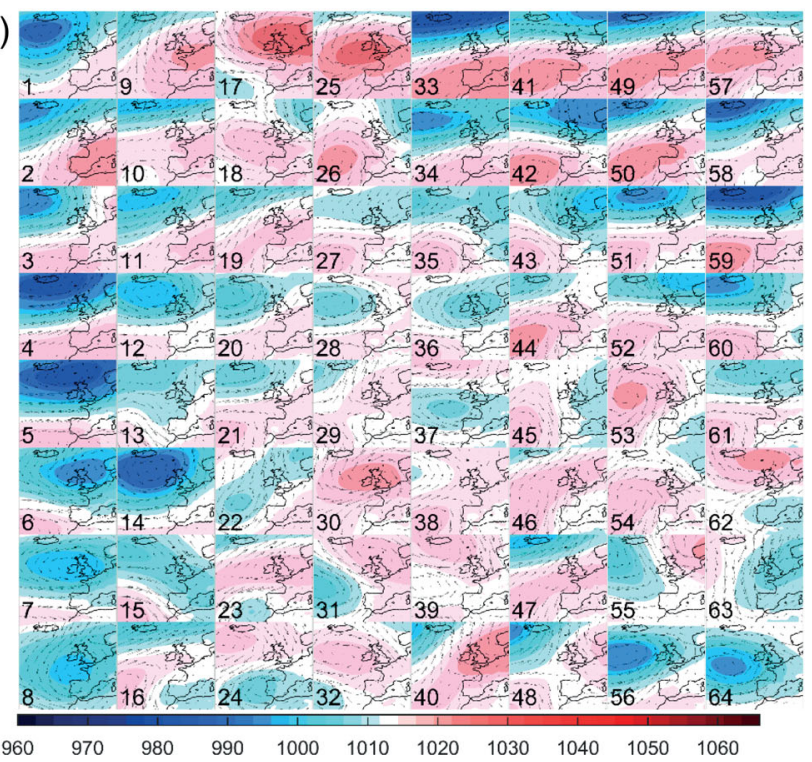

(b)

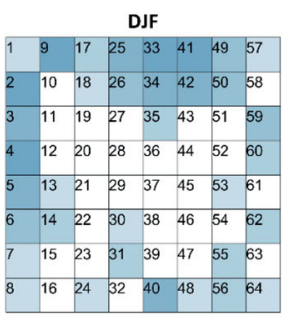

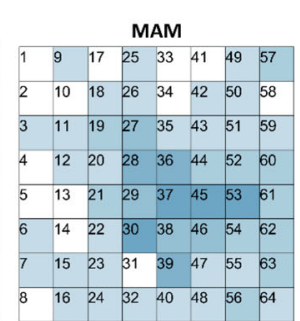

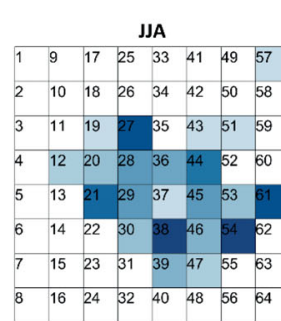

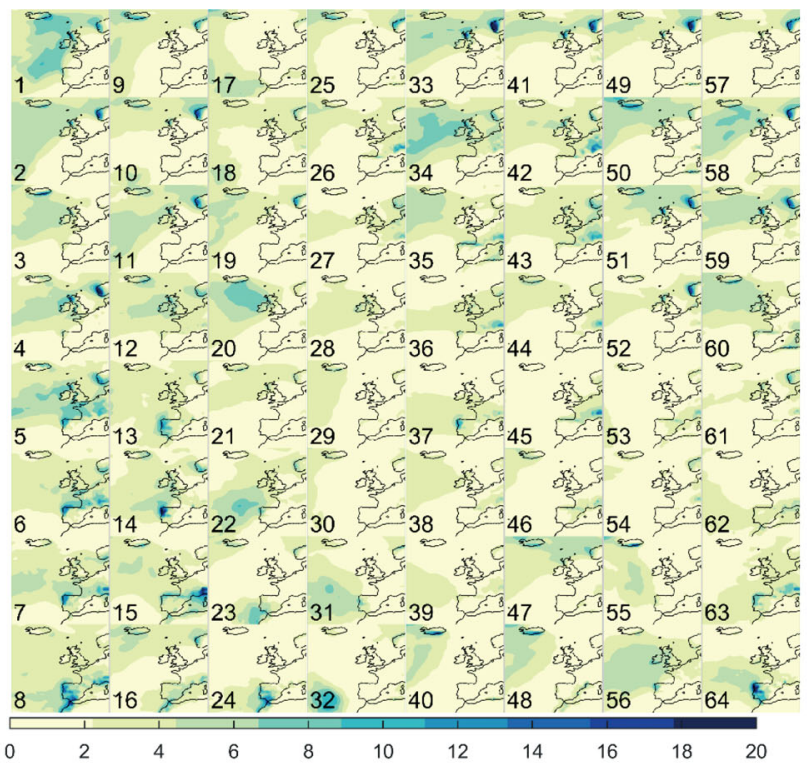

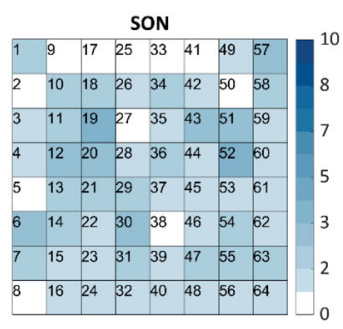

(c)

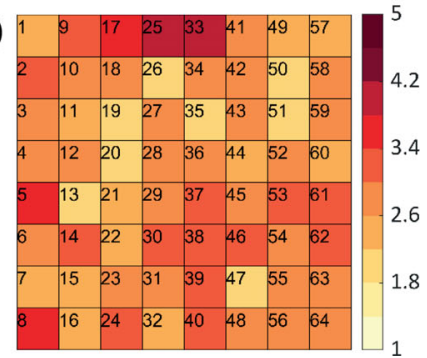

F I G URE 3 (a) $8 \times 8$ weather types (WTs) represented by the sea-level pressure, in hPa, wind (left panel) and precipitation, in mm, (right panel) fields at Day 1 obtained from the predictor classification for European locations; (b) seasonal occurrence probability (\%) of WTs (in blue scale); (c) duration in days of the WT persistence (in red scale) [Colour figure can be viewed at wileyonlinelibrary.com]

\section{5 | LINKING COMPOUND EVENTS AND SYNOPTIC WEATHER PATTERNS}

\section{1 | European coastlines}

Figures 5 and 6 show the link between the identified CEs at the three locations selected along each of the North Atlantic European coastlines and the respective WTs. Figure 5 displays the scatter plot of $Q$ and $S$, with WSE represented by the dot colour, of those CEs generated by synoptic situations within each WT. Figure 6a shows the probability of CEs associated with each WT, while Figure $6 \mathrm{~b}$ shows the probability of occurrence of these WTs, and Figure $6 \mathrm{c}$ the probability that a CE occurs given the presence of each WT for the period 1980-2014. This latter probability is calculated by dividing the occurrence probability of each WT between its mean persistence to avoid counts belonging to the same storm.

At the Scottish river (location 1 in Figure 2a), CEs are generated mainly by two patterns, WT4 and WT5, which correspond to 10 and 13 events, respectively, from a total of 40 events (see Figures 5-1 and 6a1). These two patterns resemble the NAO spatial mode, which is characterized by a strengthening of the low over Iceland and the high around the Azores (Portugal). There are several differences between these WTs. WT5 is a north-south dipole with horizontal winds, while in WT4, the dipole is oriented northwest-southeast and consequently experiences winds from the southwest. A more eastern location of the low-pressure centre in the case of WT5 could explain why the CEs associated with WT5 present a higher skew surge. We calculate for each WT which WT occurs on the following day. These results, in terms of their probability and represented in a square matrix, define the transition probability matrix. This matrix describes the transition of each WT on the following day, which can be to remain in the same WT (persistence) or to progress to different ones. The diagonal dominance of the transition probability matrix indicates that the most common behaviour is to remain in the same WT (see Figure S3). In the case of WT4, the transition matrix also reveals that there is a significant probability to evolve to WT5. The occurrence probability of these WTs is around $1.2 \%$ due to their 
(a)
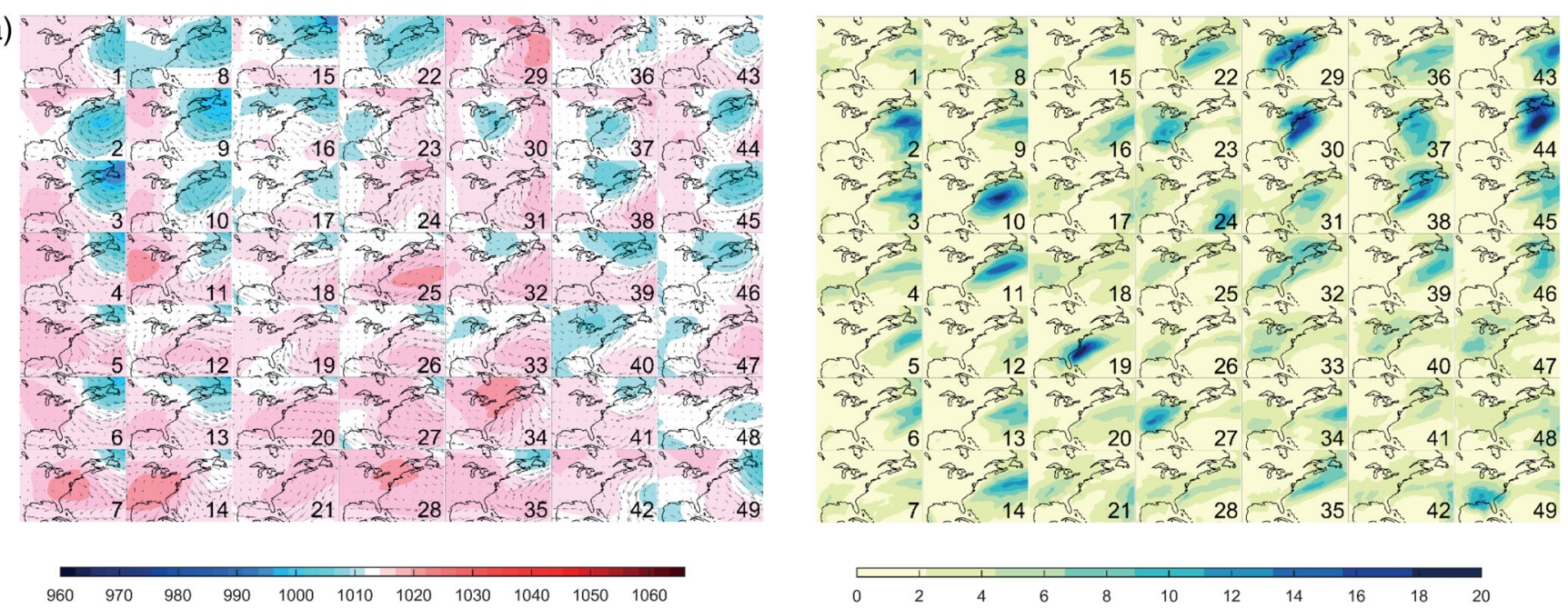

(b)

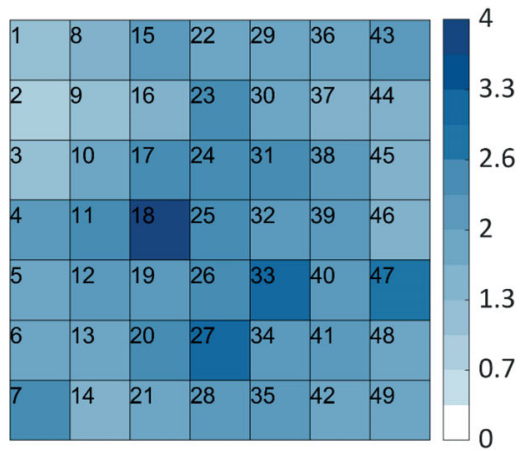

(c)

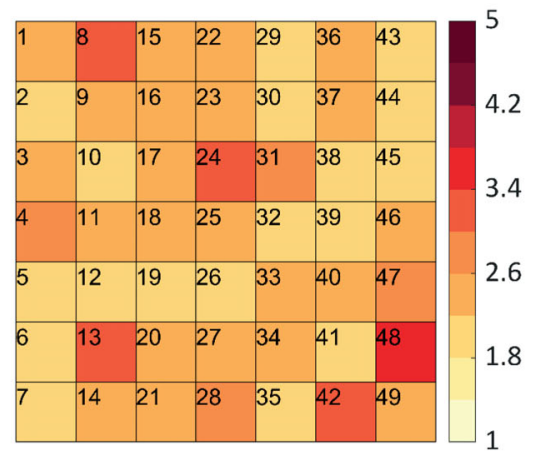

F I G U RE 4 (a) 7×7 weather types (WTs) represented by the sea-level pressure, in hPa, wind (left panel) and precipitation, in mm, (right panel) fields at day 1 obtained from the predictor classification for North American locations at extratropical season; (b) DJFMAM occurrence probability (\%) of WTs (in blue scale); (c) duration in days of the WT persistence (in red scale) [Colour figure can be viewed at wileyonlinelibrary.com]

extremeness (see Figure 6b1), whereas the probability that a CE occurs is around $15 \%$ for WT4 and $28 \%$ for WT5 (see Figure 6c1). Three-day dynamic WT5 pattern gives information about the evolution of the precipitation driver which is more intense during the preceding day or 2 days to the subsequent $\mathrm{CE}$ episode (Figure S2). The analysis of the different storms represented by these two patterns reveals different spatial distributions of precipitation in the case of WT4 along the tight gradient of high-low pressure.

CEs are less frequent in the estuary of Douro River (location 2 in Figure 2a) at the western coast of the Iberian Peninsula, and they are generated by a wider variety of atmospheric conditions. Three distinctive WTs are the main synoptic patterns associated with CEs, namely WT64, WT14 and WT8, with 7, 6 and 5 events, respectively (see Figures 5-2 and 6a2). Precipitation is restricted to the geographical area of the study site, especially in WT14 and WT64 with high low-pressure systems located further from the coast, while WT8 is characterized by more local systems which usually generate higher storm surges. Only in around 15-25\% of the occurrence of these synoptic patterns, was a CE identified (see Figure 6c2).

In the Moroccan River (location 3 in Figure 2a), most of the CEs are associated to WT8 and WT24, with 20 and 7 events out of a total of 46, respectively (see Figures 5-3 and 6a3). WT8 is characterized by a medium lowpressure system centred around the north-west corner of the Iberian Peninsula accompanied with a spatial pattern of precipitation that covers the whole western Iberian Peninsula, with more intense rainfall over the Strait of Gibraltar. WT24 is defined by a less intense and smaller low-pressure system towards the south, with heavy precipitation localized in the most southern area of this subdomain during the 3 days considered in the definition of the dynamical predictor. There is a probability of around $90 \%$ that WT8 is associated with the occurrence of a CE (see Figure 6c3).

The number of CEs associated with each WT has been calculated for all locations along the North Atlantic European coastlines (see Figure 7). Note that Figure 7 only includes instances where the number of events is 
1

\begin{tabular}{|l|l|l|l|l|l|l|l|}
\hline 1 & 9 & 17 & 25 & 33 & 41 & 49 & 57 \\
\hline 2 & 10 & 18 & 26 & 34 & 42 & 50 & 58 \\
\hline 3 & 11 & 19 & 27 & 35 & 43 & 51 & 59 \\
\hline 4 & 12 & 20 & 28 & 36 & 44 & 52 & 60 \\
\hline 5 & 13 & 21 & 29 & 37 & 45 & 53 & 61 \\
\hline 6 & 14 & 22 & 30 & 38 & 46 & 54 & 62 \\
\hline 7 & 15 & 23 & 31 & 39 & 47 & 55 & 63 \\
\hline 8 & 16 & 24 & 32 & 40 & 48 & 56 & 64 \\
\hline
\end{tabular}
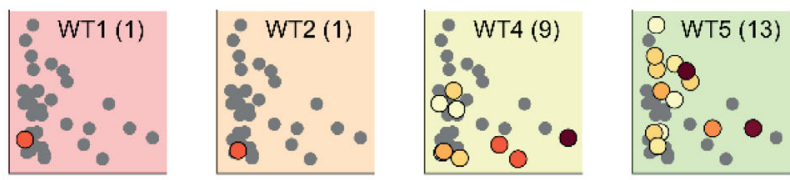

2.62

2.56

2.5

2.44
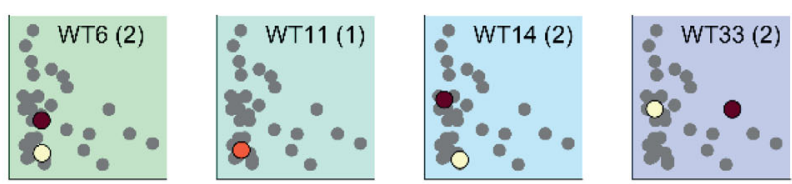

2.38

2.32

2.26

2.2
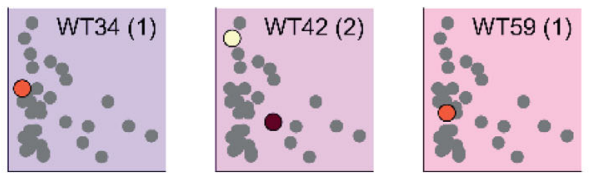

2.14

2.08

2.02

\begin{tabular}{|l|l|l|l|l|l|l|l|}
\hline 1 & 9 & 17 & 25 & 33 & 41 & 49 & 57 \\
\hline 2 & 10 & 18 & 26 & 34 & 42 & 50 & 58 \\
\hline 3 & 11 & 19 & 27 & 35 & 43 & 51 & 59 \\
\hline 4 & 12 & 20 & 28 & 36 & 44 & 52 & 60 \\
\hline 5 & 13 & 21 & 29 & 37 & 45 & 53 & 61 \\
\hline 6 & 14 & 22 & 30 & 38 & 46 & 54 & 62 \\
\hline 7 & 15 & 23 & 31 & 39 & 47 & 55 & 63 \\
\hline 8 & 16 & 24 & 32 & 40 & 48 & 56 & 64 \\
\hline
\end{tabular}
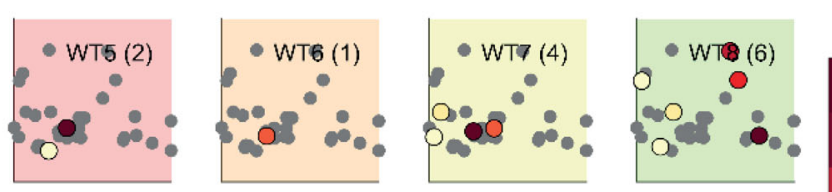

6.52

6.23

5.93

5.63
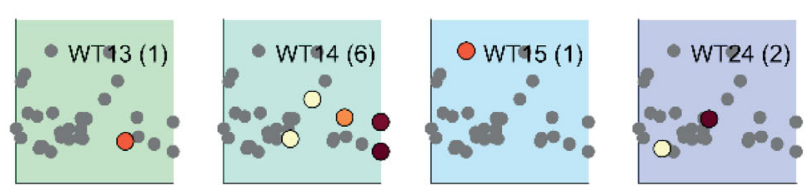

5.33

5.04

4.74

4.44
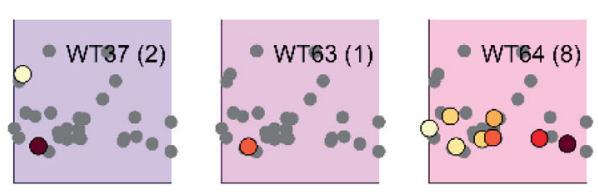

4.14

3.85

3.55

\begin{tabular}{|l|l|l|l|l|l|l|l|}
\hline 1 & 9 & 17 & 25 & 33 & 41 & 49 & 57 \\
\hline 2 & 10 & 18 & 26 & 34 & 42 & 50 & 58 \\
\hline 3 & 11 & 19 & 27 & 35 & 43 & 51 & 59 \\
\hline 4 & 12 & 20 & 28 & 36 & 44 & 52 & 60 \\
\hline 5 & 13 & 21 & 29 & 37 & 45 & 53 & 61 \\
\hline 6 & 14 & 22 & 30 & 38 & 46 & 54 & 62 \\
\hline 7 & 15 & 23 & 31 & 39 & 47 & 55 & 63 \\
\hline 8 & 16 & 24 & 32 & 40 & 48 & 56 & 64 \\
\hline
\end{tabular}

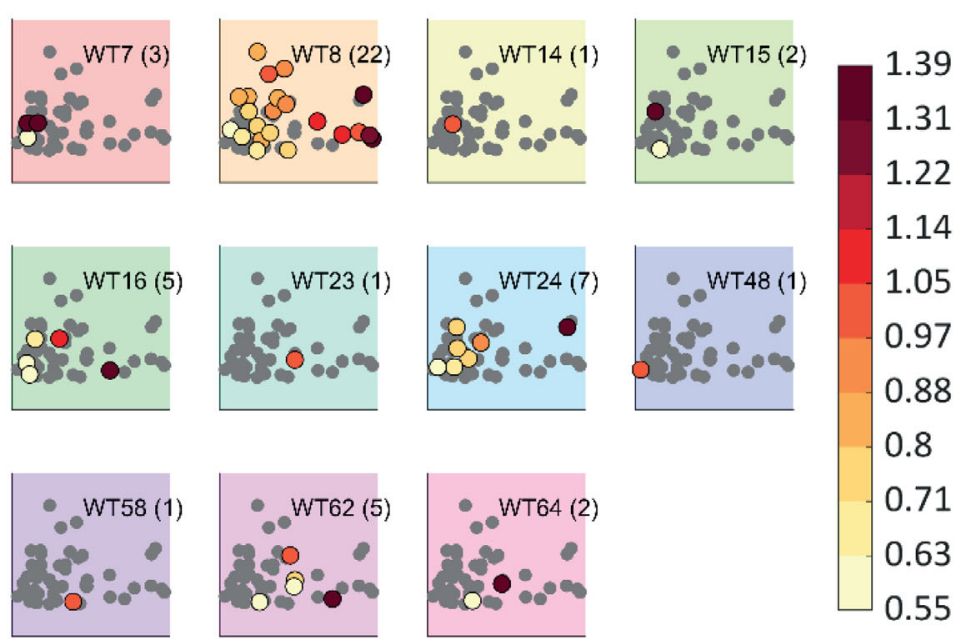

F I G U RE 5 Weather types (WTs) linked to compound events (in colour) of the European WT classification (Figure 3) and the corresponding scatter plot of river discharge versus skew surge (water surface elevation, in $\mathrm{m}$, in a red scale) at the three locations selected along the North Atlantic European coastlines (locations 1, 2, and 3 in Figure 2a) [Colour figure can be viewed at wileyonlinelibrary.com] 


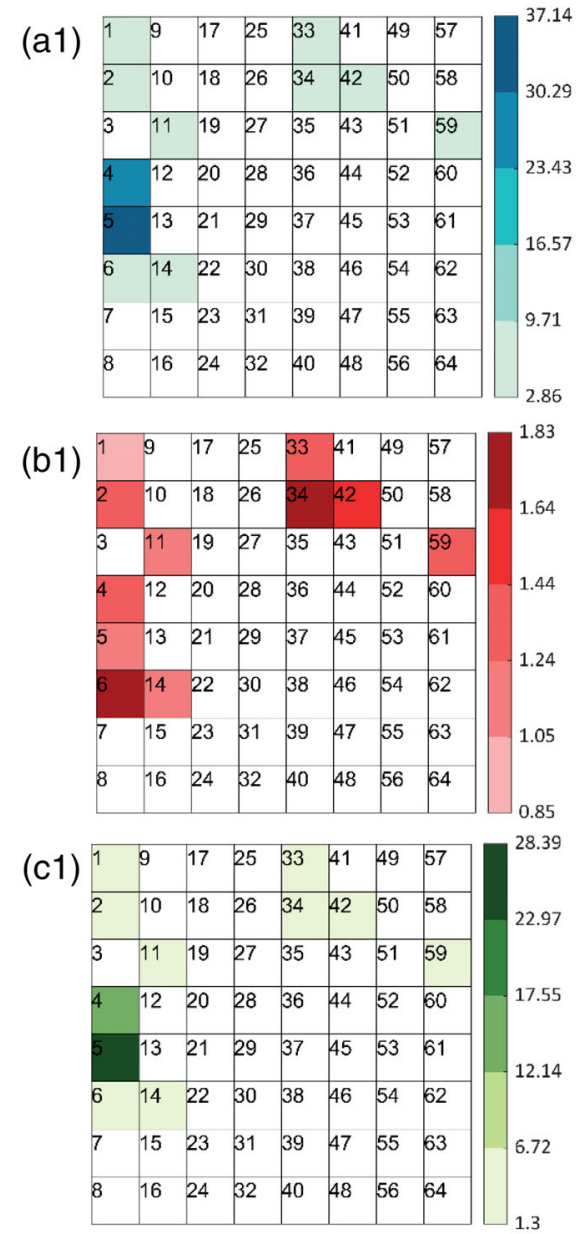

(a2)

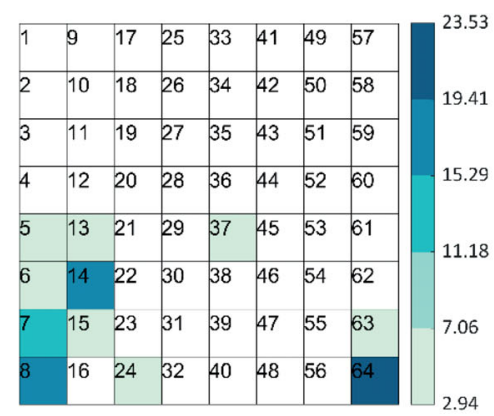

(a3)

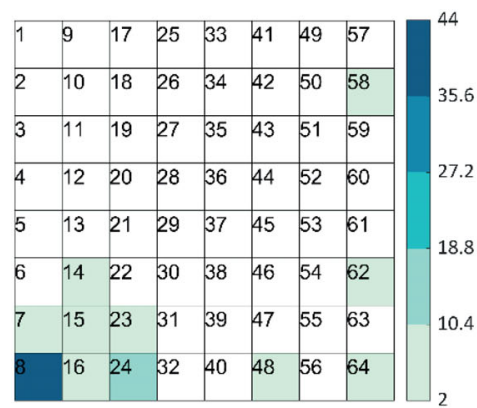

(b2)

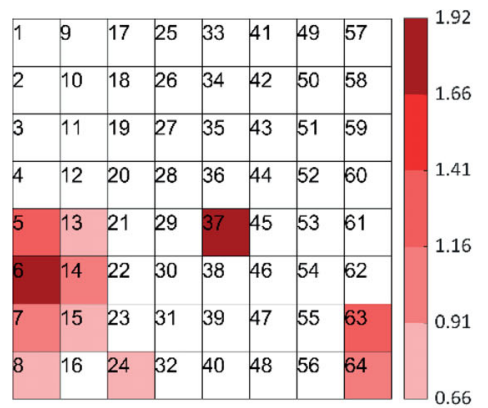

(b3)

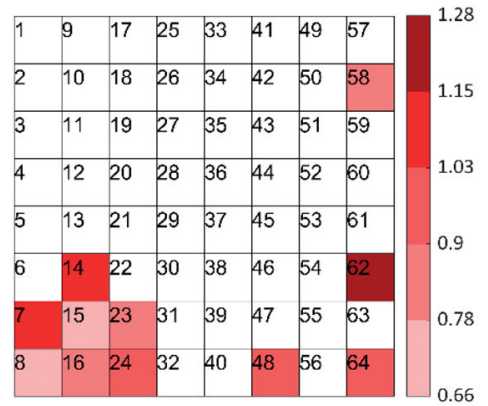

(c2)

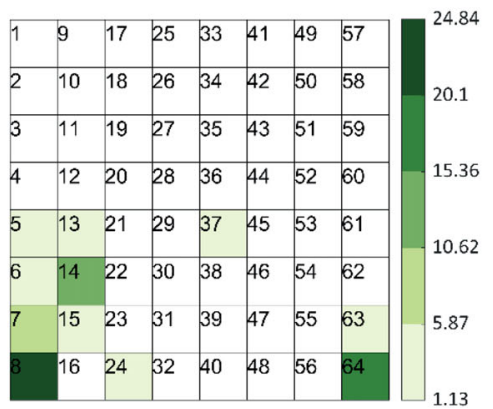

(c3)

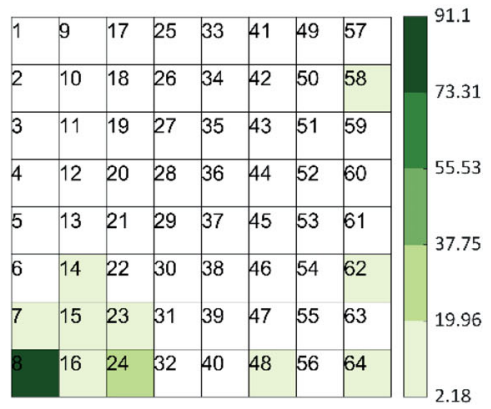

F I G U RE 6 Results for three locations selected along the North Atlantic European coastlines (locations 1, 2, and 3 in Figure 2a) for the European weather type (WT) classification (Figure 3): (a) probability (\%) of compound events associated with each WT; (b) occurrence probability (\%) of each WT associated with compound events; (c) probability (\%) of getting a compound event when the associated WT occurs [Colour figure can be viewed at wileyonlinelibrary.com]

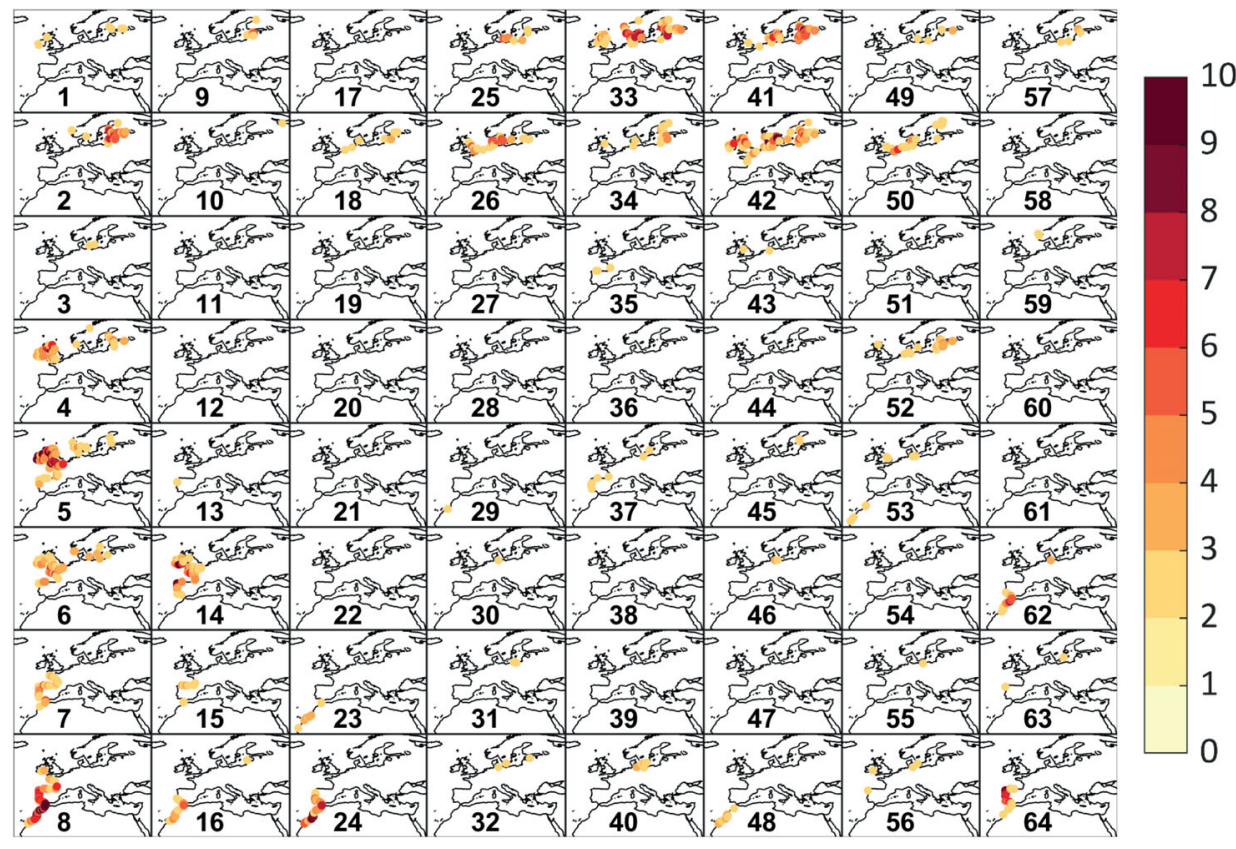

F I G U R E 7 Number of coastal compound events associated with each weather type (WT) along the European North Atlantic coastlines from 1980 to 2014 for the European WT classification (Figure 3) [Colour figure can be viewed at wileyonlinelibrary.com] 
higher than one, to avoid spurious outputs, and the scale reaches $10 \mathrm{CEs}$ as the maximum value. WTs with higher number of CEs are located in the left side of the lattice. WT4 and WT5 are mainly associated with CEs that occur along the coasts of Ireland and the west coast of the United Kingdom. Regarding WT5, the synoptic conditions represented by this pattern also generated CEs along the north coast of Spain. Similar behaviour is
1

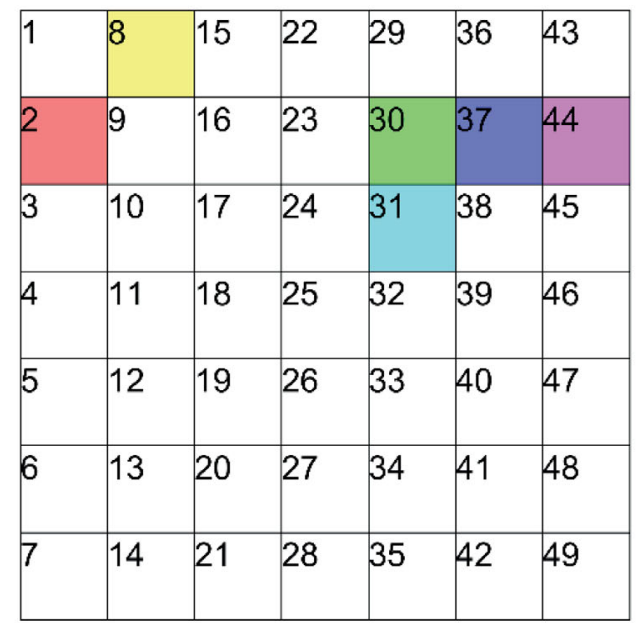

2

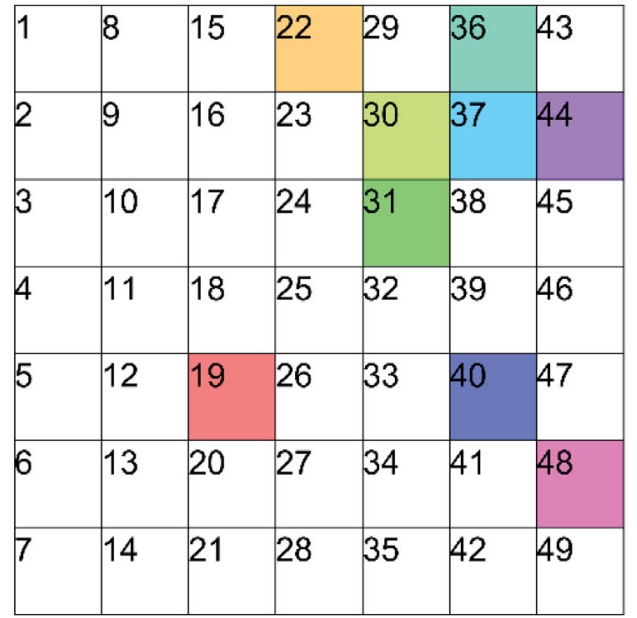

3

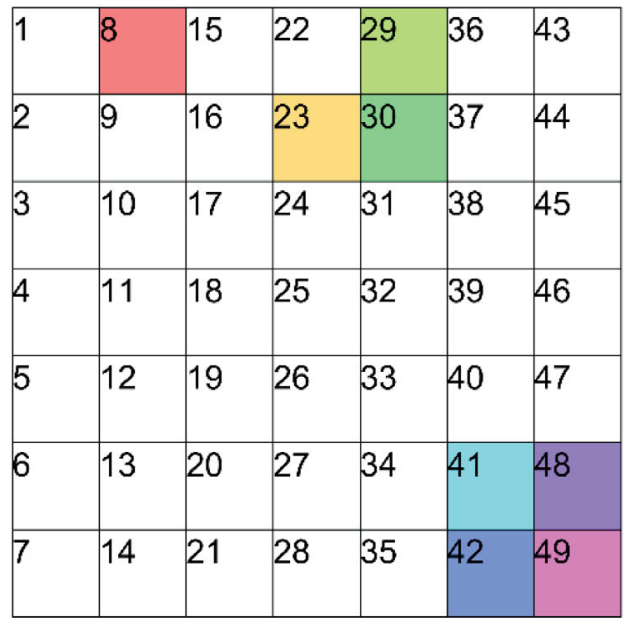

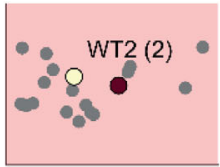
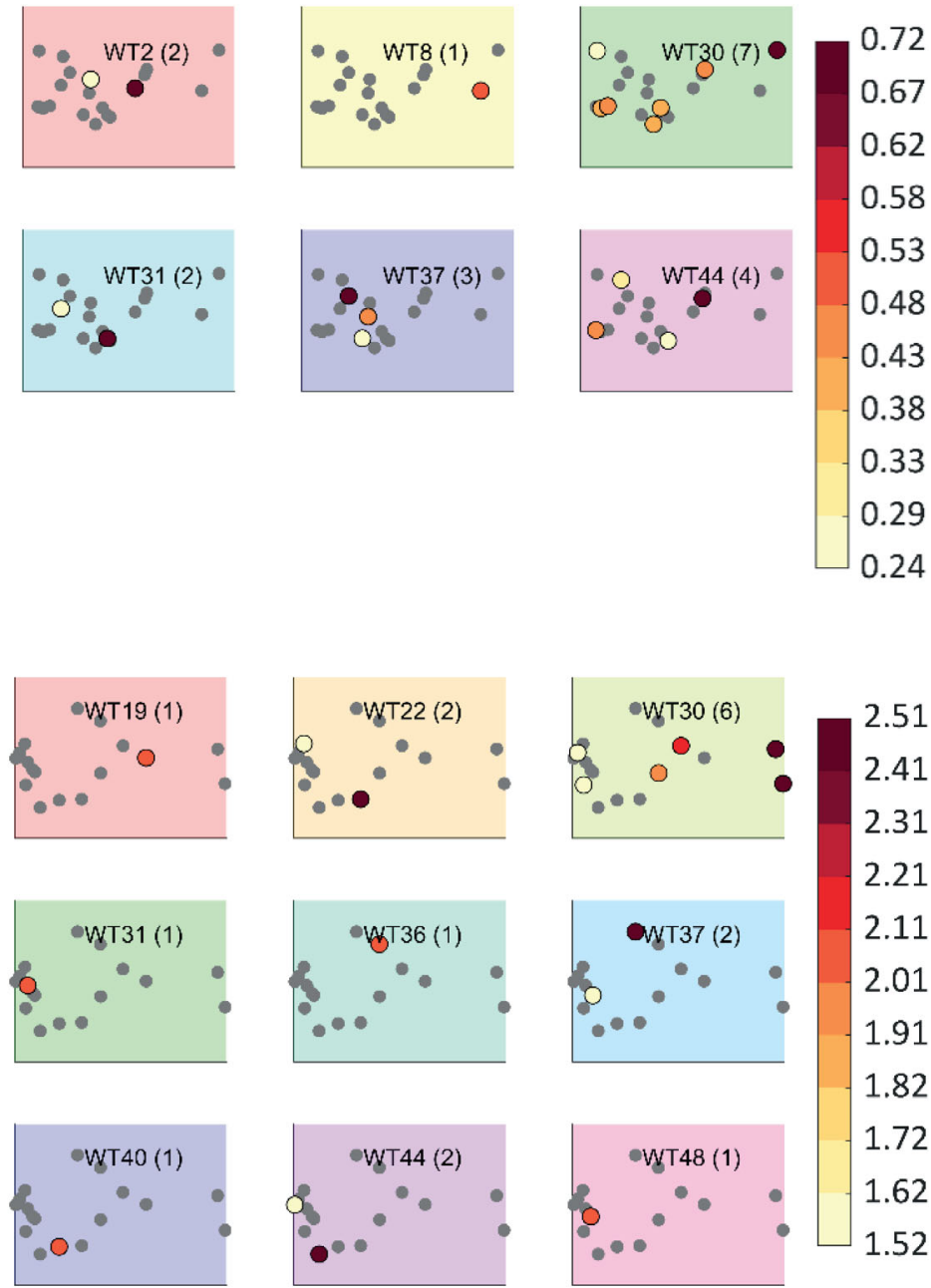

2.51

2.41

2.31

2.21

2.11

2.01

1.91

1.82

1.72

1.62

1.52
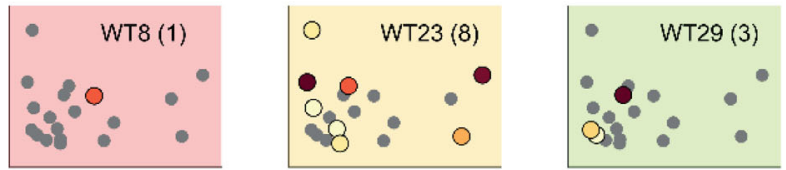

0.64

0.63

0.61

0.59
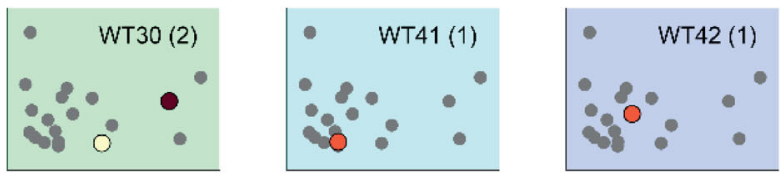

0.57

0.56

0.54

0.52
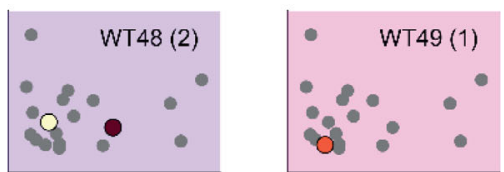

0.5

0.48

0.47

F I G U R E 8 Weather types (WTs) linked to compound events (in colour) of the U.S. WT classification (Figure 4) and the corresponding scatter plot of river discharge versus skew surge (water surface elevation, in $\mathrm{m}$, in a red scale) at three locations selected along the North Atlantic U.S. coastlines (1, 2, 3, see Figure 2b) [Colour figure can be viewed at wileyonlinelibrary.com] 
observed for WT6. This is due to the wider spatial pattern of precipitation of WT5 and WT6 compared with WT4. WT7, WT14 and WT15 are transitional patterns over the lattice, from low-pressure systems centred in the north moving to the south with localized precipitation mainly over the northwest coast of the Iberian Peninsula, which is reflected in several CEs occurring in these locations. The most important pattern regarding the number of CE occurrences is WT8, and also the extension of the corresponding spatial footprint of $\mathrm{CE}$ occurrences which covers the west coast of the Iberian Peninsula and north of Africa. Other significant patterns that have not been showed up in the analysis of the three locations are the WT33, WT41 and WT42, which are characterized by low-pressure centres in high latitudes with precipitation over the Baltic Sea and North Sea which are, therefore, linked to CEs along the coastlines of these areas.

\subsection{North American coastlines}

Figures 8 and 9 display the link between synoptic patterns and CEs at each of the three selected locations over the North Atlantic American coastlines. The main synoptic-scale compound flooding potential WT (WT30) is common to the three locations, albeit with different associated CE occurrence. This pattern is characterized by low-pressure systems generated in the south of the predictor domain that move northward along the northeast American coastline (see Figure S4). In the case of Occuquan River (location 1 in Figure 2b), around 37\% of CEs (from a total of 19 events, see Figure 8-1) are associated with this WT, which occurs only around $12 \%$ of the time (see Figure 9c1). WT37 and WT44, which are characterized by low-pressure systems centred northward, are also representative of compound flooding patterns in this location, with a CE occurrence of around 25-30\% (b1)

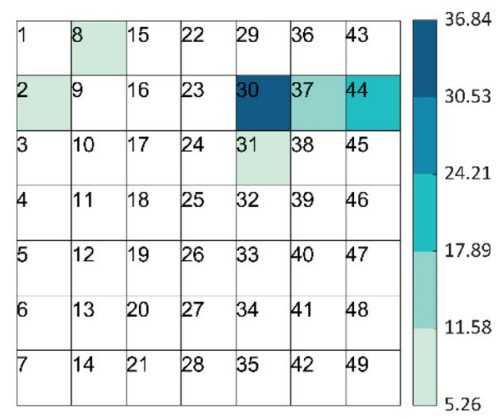

(c1)

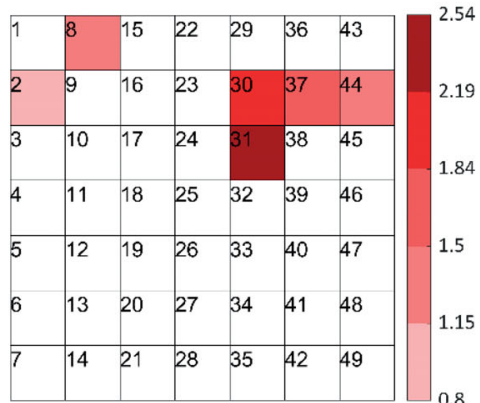

(d1)

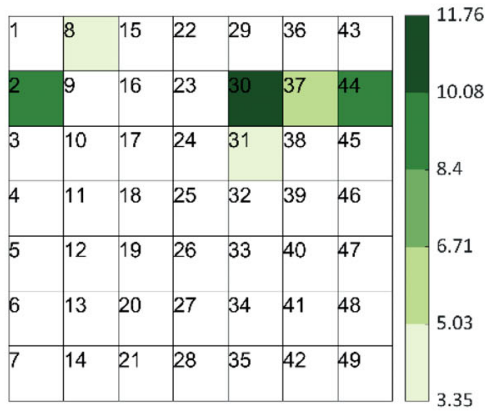

(b2)

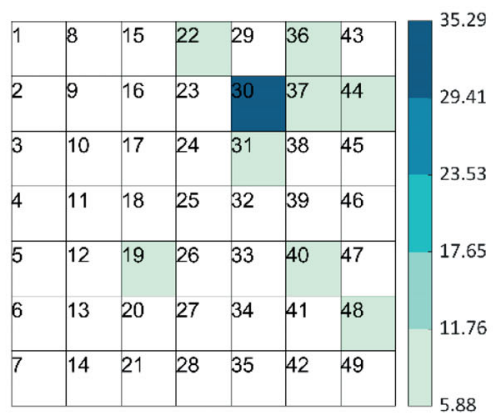

(c2)

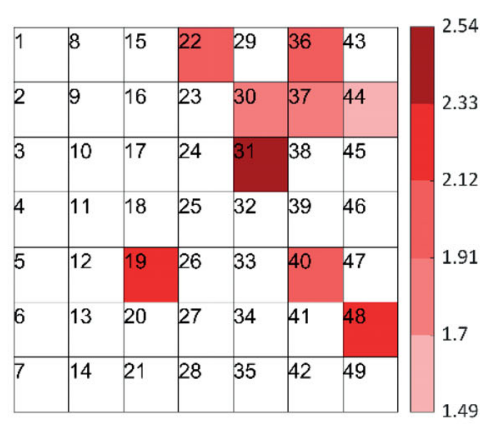

(d2)

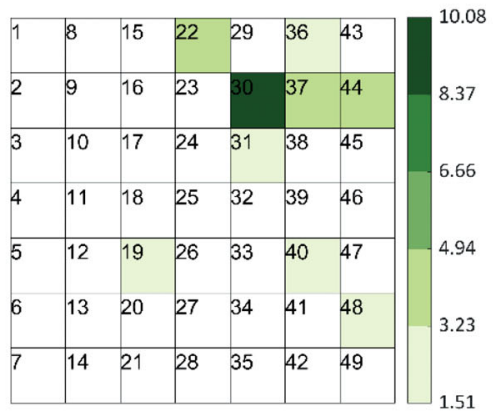

(b3)

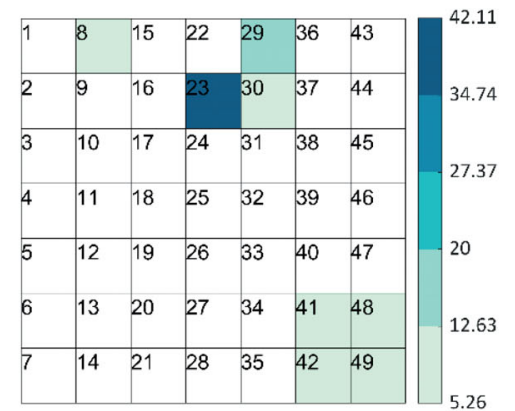

(c3)

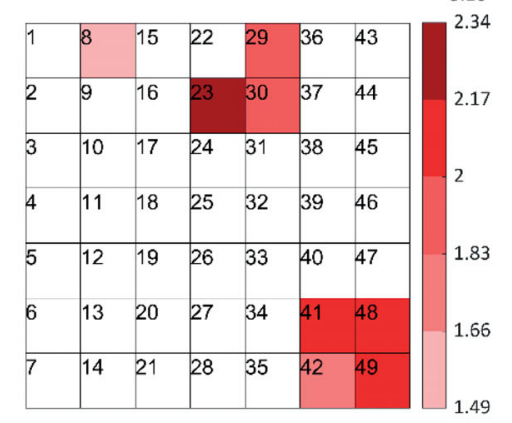

(d3)

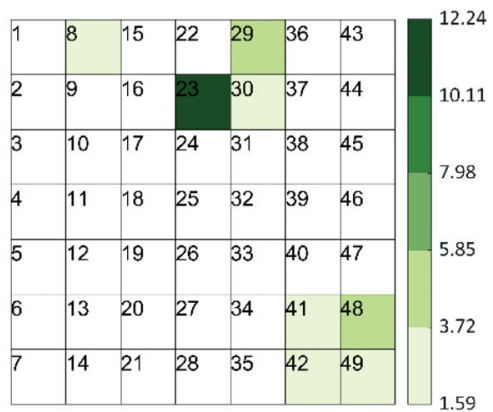

F I G U R E 9 Results at three locations selected along the North Atlantic U.S. coastlines (1, 2, 3, see Figure 2b) for the U.S. weather type (WT) classification (Figure 4): a) probability (\%) of compound events associated with each WT; (b) occurrence probability (\%) of each WT associated with compound events; (c) probability (\%) of getting a compound when the associated WT occurs [Colour figure can be viewed at wileyonlinelibrary.com] 
(see Figure 9c1). In estuary of North Santee River (location 2 in Figure 2b), the highest number of CEs (around $36 \%$ of a total of 17) and the highest probability that a CE is generated when this WT occurs ( $10 \%$ of the time) are also associated with WT30. WT37 and WT44 are also identified as compound flooding patterns, as in location 1 , with $11 \%$ of CEs associated with each WT and a probability that a CE occurs limited to 5\% (see Figure 9c2). In the estuary of Pearl River (location 3 in Figure 2b), the main compound flooding pattern is WT23, representing synoptic conditions defined by a local low system over the coast of the Gulf of Mexico which generates southeast winds with heavy localized precipitation. The corresponding probability of CEs is around $42 \%$ of a total of 19 events (see Figures 8-3 and 9a3) and the probability that a CE arises when these WTs occur is around $12 \%$ (see Figure 9c3). The second WT in terms of associated CE occurrence at location 3 is WT29, with a probability of around $20 \%$ but with a probability that a CE occurs when this atmospheric situation is presented being lower than $6 \%$. This pattern is not characterized by a low system, but intense southeast winds $\mathrm{CE}$ that might generate high sea levels accompanied by heavy localized rainfall during the same day and the two preceding days. In this case, the transition probability matrix shows that, besides the high probability of persisting in the same WT, there is a similar probability that WT23 progresses to WT30, and the WT30 to WT44 (see Figure S5).

The distribution of the number of CEs along the North Atlantic American coastlines associated with each WT is shown in Figure 10. WT23, WT30 and WT37, located on the right of the second row of the lattice, and identified in the analysis of the three selected locations, are revealed as the synoptic patterns with the highest number of CEs along the southern coast of the Gulf of Mexico and the central eastern U.S. coastline. The stretch of the coastline where CEs occur are conditioned to the spatial distribution of precipitation associated with each of these patterns and the location of the low systems. When the total CE occurrence is divided in WTs, other WTs emerge, such as WT39 and WT46 which are associated with CEs that occur along the coastline from New Jersey to Maine. Although the total number of CEs in this area is low, the within-WT occurrence is comparable to other locations because it is mainly concentrated in these two WTs. Besides WT23, which was identified in the analysis of location 3, WT49 is also linked with high $\mathrm{CE}$ occurrence in locations along the coast of the Gulf of Mexico. This pattern is defined by localized intense precipitation during the previous and same day as the $\mathrm{CE}$ coexisting with southeastern winds, similar to WT29 but with much more localized rainfall.

\section{I ANALYSIS OF THE INTERANNUAL VARIABILITY OF OCCURRENCES OF COASTAL COMPOUND EVENTS}

Figure 11a shows the Kendall rank correlation coefficient between the annual winter (DJFM) occurrence of WTs in the European domain and the NAO winter index, Figure 11b shows the correlation between the number of CEs at each study site associated with each WT and the
FIG URE 10 The number of coastal compound events associated with each weather type (WT) along the North Atlantic U.S. coastlines from 1980 to 2014 for the U.S. WT classification (Figure 4) [Colour figure can be viewed at wileyonlinelibrary.com]

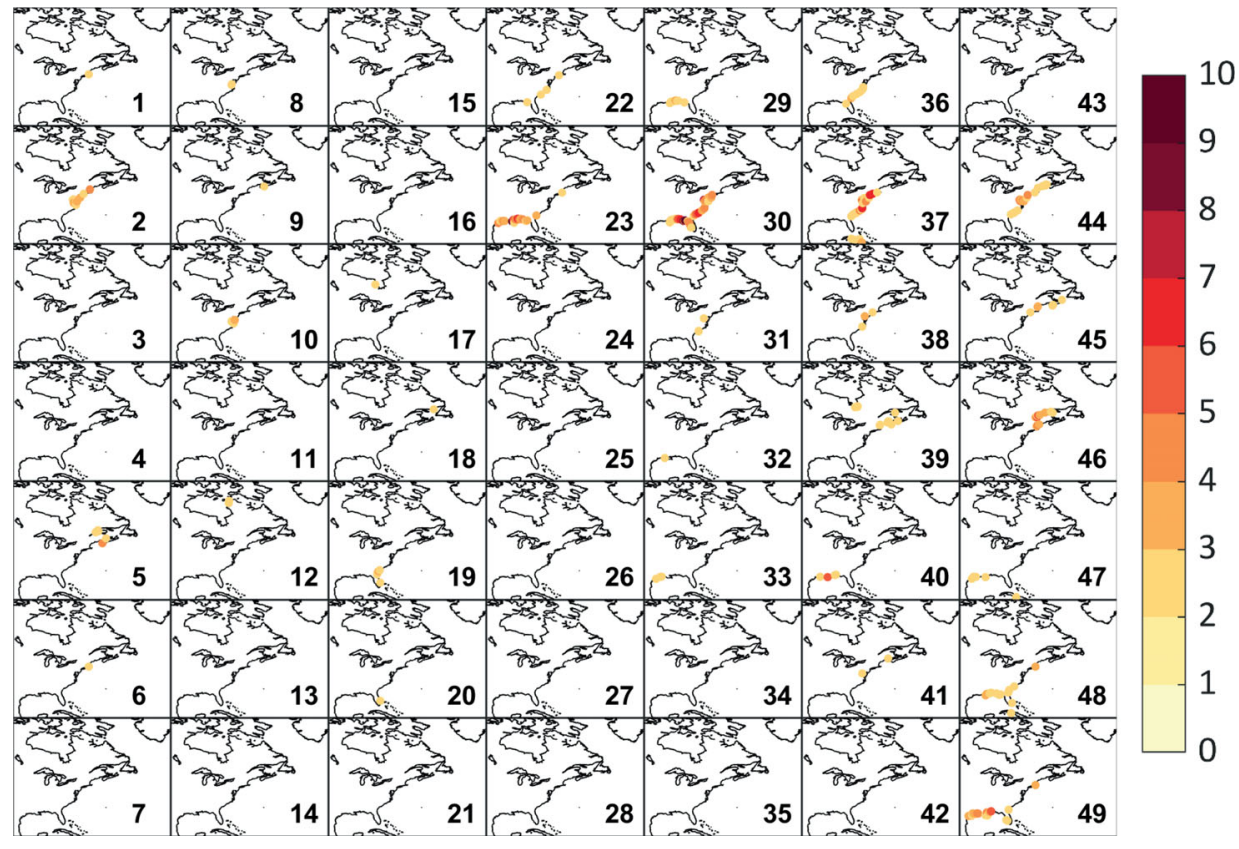


NAO winter index. WT and CE occurrences represent discrete variables, which complicate the analysis to provide a robust and significant correlation value. Small random magnitudes are added to the occurrences and the final results are calculated from 1,000 simulations. Figure S7 shows some examples of the correlation between time series of the winter occurrence of certain WTs and the NAO or WEPA index. Figure S8 shows some examples of the correlation between the number of CEs that occur during winter associated to a certain WTs and the NAO or WEPA index.

Correlation between the NAO index and the CE occurrence is limited to lower WTs than the correlation between the NAO index and the WT occurrence because a CE is not always generated when the associated WT occur. Only certain variability, represented by maximum correlation coefficients of the order of 0.4 , of the $\mathrm{CE}$ occurrence at locations in the south of Ireland and United Kingdom and on the north coast of France are explained by the NAO index. These CEs are associated mainly with WT4, WT5 and WT6, which its annual winter occurrence is also positively correlated (coefficients around 0.3-0.4) with the NAO index. The CE occurrence along the southwest coast of the Atlantic Ocean is associated mainly with WT8 and neighbouring WTs, being negatively correlated with the NAO index (coefficients between -0.3 and -0.4 ). A similar analysis with the WEPA index is displayed in Figure 11c,d. In this case, the link between the CE occurrence and this climate index is concentrated in WT5 and WT6 along the southwest coast of Ireland and United Kingdom, with an intensification of the positive correlation (coefficients around 0.3-0.4 in higher number of locations) as compared to the NAO index. (a)

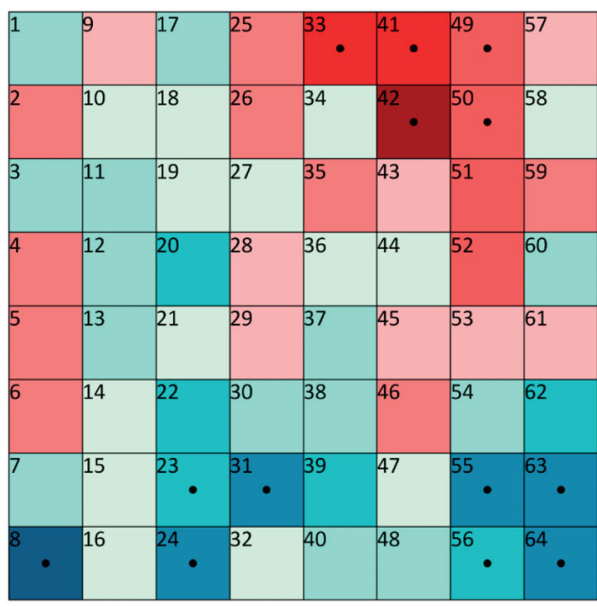

(c)

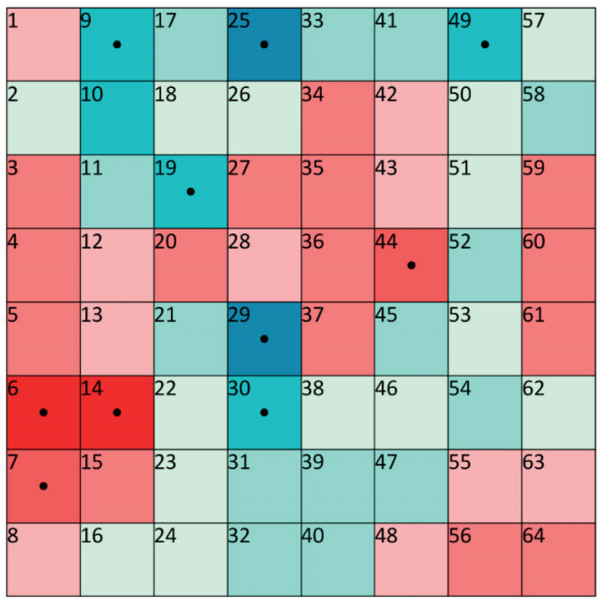

(b)

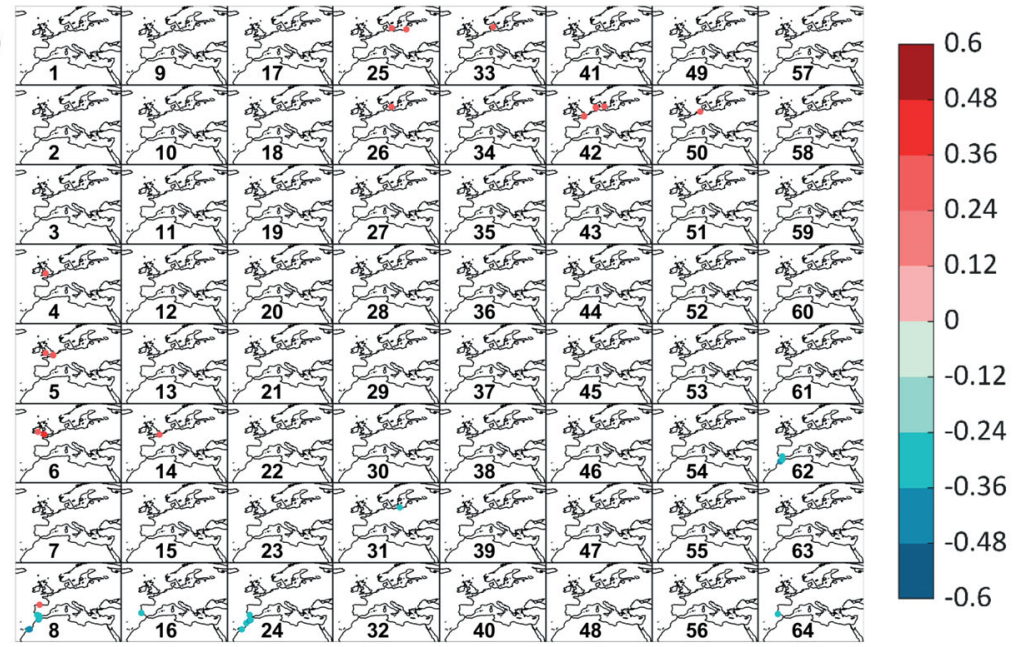

(d)

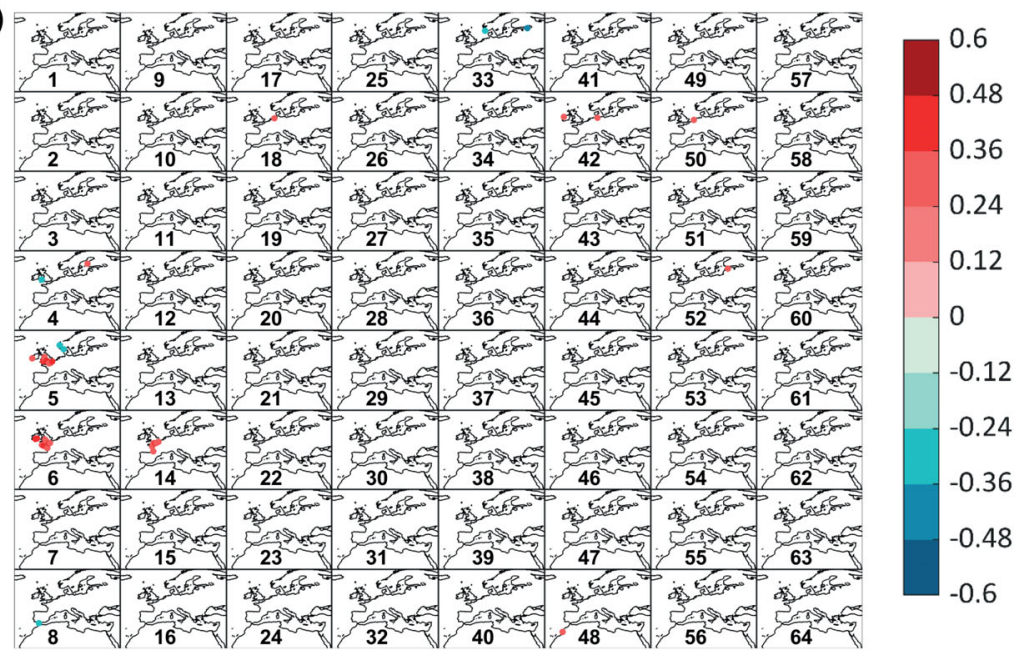

F I G U RE 11 (a) Correlation between weather type (WT) occurrence and NAO winter index (significant marked with a dot); (b) correlation between the occurrence of coastal compound events and NAO winter index (only significant shown) along European coastlines; (c, d) same for WEPA index, for the European WT classification (Figure 3) [Colour figure can be viewed at wileyonlinelibrary.com] 
The interannual variability of $\mathrm{CE}$ occurrence with NAO and WEPA is associated with synoptic conditions represented by WT4, WT5 and WT6. These patterns are characterized by low-pressure systems centred in latitudes of around $70-60^{\circ}$, where its spatial structure is partially explained with the spatial modes of these climate indices. During the positive phase of the NAO, the SLP gradient is strengthened, which drives deep lowpressure systems passing between Greenland and Scotland that are associated with increased W-SW winds at around $60^{\circ} \mathrm{N}$. The WEPA's spatial pattern is also a latitudinal dipole but with a $\sim 15^{\circ}$ southward shift as compared with NAO (Castelle et al., 2017) which also drives a large number of deep low-pressure systems passing over Ireland and the United Kingdom. During the negative phase of the NAO, less deep southward shifted lowpressure systems occur, which explain the negative correlation with WTs located in the lower cells of the lattice and which is reflected in a negative correlation with compound event occurrences associated with WT8 and WT24.

Figure 12 shows the correlation between the occurrence of WTs within the U.S. domain (panels a and c) and the PNA or ONI index during the extratropical season, and the correlation between the number of CEs that occur during this season at each study site associated with each WT (panels b and d) and the PNA or ONI index (panels a and b or $c$ and d, respectively). Only variability in the occurrence of CEs associated with WTs 23, 30 and 37 at study sites mainly located at the southern stretch of the eastern U.S. coast show significant teleconnections. The correlation is practically restricted to WT37 and the central area of the eastern U.S. coast in the case of the PNA index. (a)

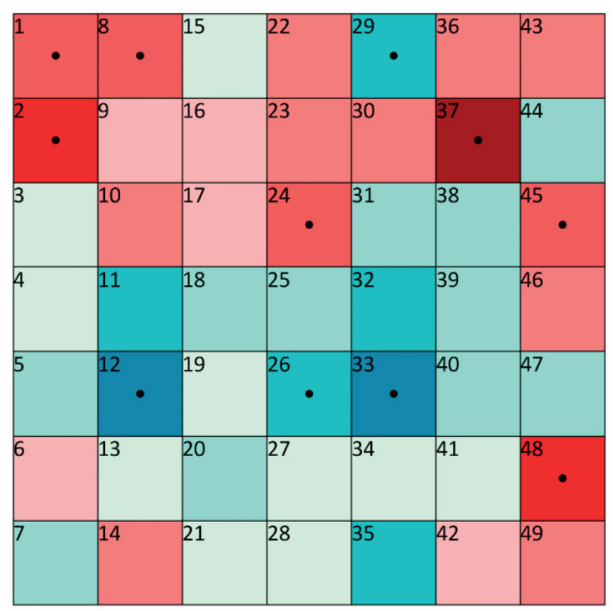

(c)

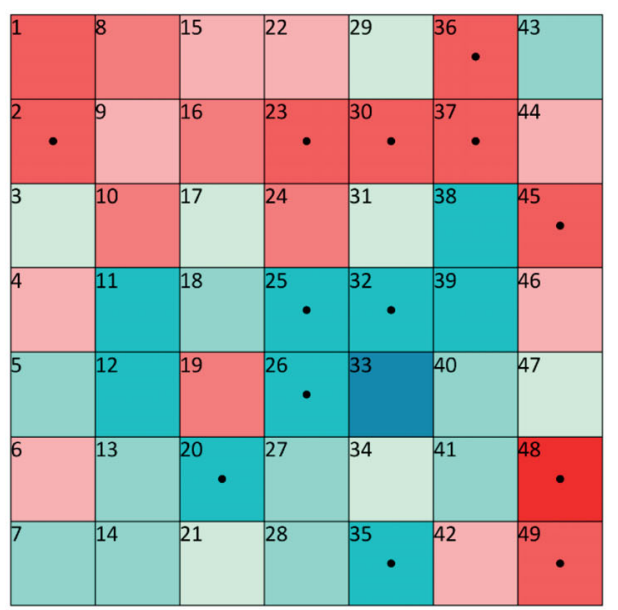

(b)

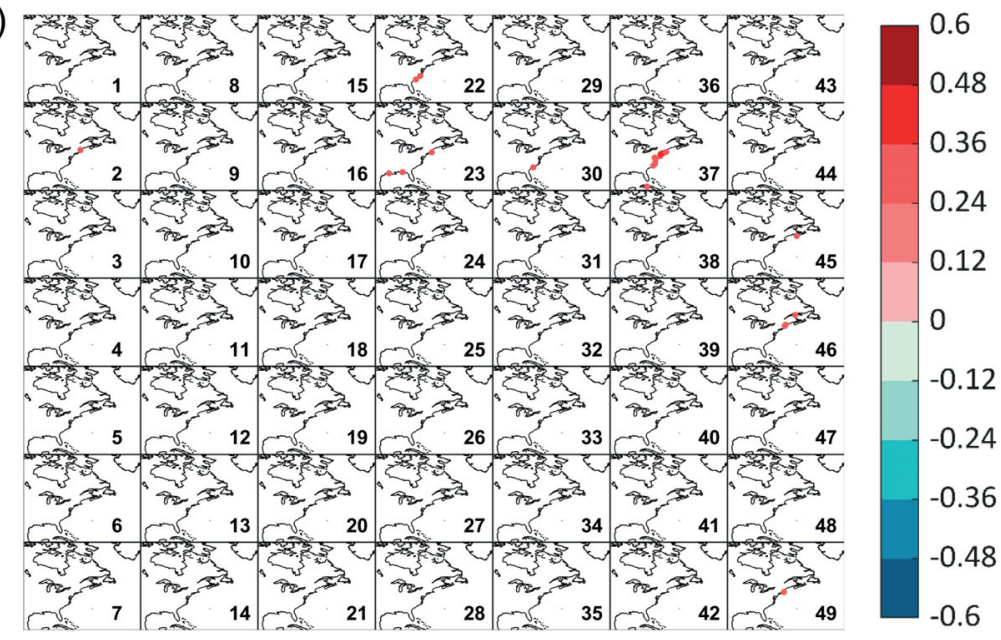

(d)

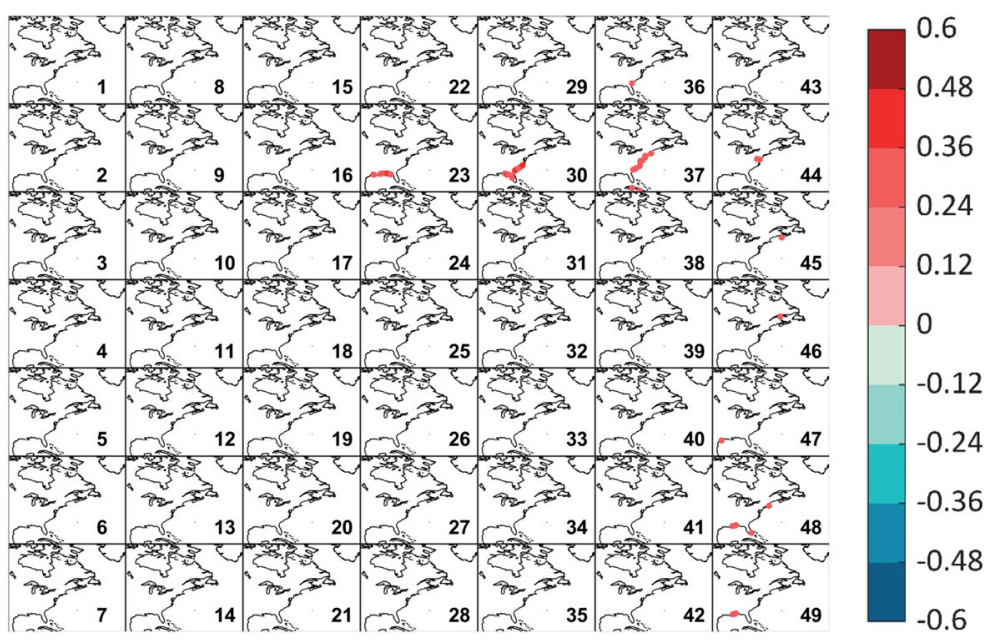

F I G U RE 12 (a) Correlation between weather type (WT) occurrence and PNA index (significant marked with a dot) during extratropical season; (b) correlation between the occurrence of coastal compound events and PNA index (only significant shown) along U.S. coastlines during this season; (c, d) same for ONI index, for the U.S. WT classification (Figure 4) [Colour figure can be viewed at wileyonlinelibrary.com] 
During a positive PNA phase, the polar jet stream across North America is stronger and farther south, within a large-scale trough, and extended southwest to northeast, supporting more cyclone activity along the coast, with a more distinct, less dispersed, storm track (Notaro et al., 2006). Therefore, a positive correlation between WT occurrence and PNA index is found in those WTs which characterize low-pressure centres along the eastern U.S. coastline, with the highest correlation with WT37 (maximum correlation close to 0.6 ). This relationship is reflected in the positive correlation (coefficient around 0.3-04) between CE occurrence associated to this WT and PNA index in the mid-eastern U.S. coastline.

East Coast winter storms are known to increase during El Niño events (Hirsch et al., 2001), with lower atmospheric pressures (Trenberth and Caron, 2000) and greater cyclone activity more common throughout the southern United States during the winters (Kunkel and Angel, 1999). The higher WT occurrence during the positive phase of the ONI index is reflected in a positive correlation around 0.3 in WTs 23,30 and 37 which is revealed in a positive correlation (coefficient around 0.30.4 ) with $\mathrm{CE}$ occurrence along the southern coast of the Gulf of Mexico, the coast of Florida and the U.S. eastcentral coast, respectively.

\section{7 | DISCUSSION}

We have found considerable differences between American and European coastlines, with the occurrence of CEs being more frequent in Europe. The analysis is done for the whole year in Europe; however, most of the CEs (around 90\%) occur in the extratropical season. In European coastlines, the distribution of the highest $\mathrm{CE}$ occurrence is concentrated along the west coast of the Iberian Peninsula and southern coast of the study domain, in line with previous results in Camus et al. (2021) and Couasnon et al. (2020), based on the dependency between drivers. The west coast of the United Kingdom and certain locations at the North and Baltic Seas, detected by Eilander et al. (2020) and Ganguli et al. (2020) as compound-dominant, have also been found to be CE "hotspots" in this study. Regarding the east coast of North America, the areas with the highest frequency of CEs are located around latitudes $35^{\circ}-40^{\circ}$ and along the Gulf of Mexico, with the occurrence being half that compared with Europe. These areas were also detected as the ones with the highest correlation between sea level and precipitation in Wahl et al. (2015), while correlations between river flows and surges is more spatially diverse (Moftakhari et al., 2017).
We have applied an approach based on WTs to identify the daily synoptic conditions associated with the occurrence of CEs. This approach is different to previous analyses of the weather conditions associated with coastal compound flooding events. Specifically, weather patterns are here defined without intervention of the flooding hazard and drivers, while in other studies (Wahl et al., 2015; Hendry et al., 2019) they are defined as the composite of the weather situations that have caused CEs. The subset of CEs can be split into several WTs using this weather-typing approach which allows us, in this case, discrimination of the diverse synoptic conditions that generate CEs. However, the predictor composite based on the occurrence of CEs could gather weather situations that they do not resemble. Another advantage of the WT approach is that a common classification of weather patterns can be used for the analysis of the occurrence of CEs along a regional coastline influenced by similar synoptic weather conditions. This attribute allows detection of the number of locations that share the same WTs linked to CEs, providing information about the CE spatial footprints. Besides, the organization of weather patterns in a lattice provides a clearer visualization of how the CE occurrences at adjacent coastal locations are associated with similar WTs. Moreover, the WT transition matrix allows to track if WTs associated with CEs in contiguous locations are coming from the same storm moving along the coastline. We found that this behaviour is more evident along the U.S. coastlines, because Atlantic cyclones generally either travel parallel to the coastline towards the NE or diverge from the coast and follow the northern boundary of the Gulf Stream eastward (Colucci, 1976). The poleward direction of storm tracks over the eastern U.S. is also reflected in the elongation from southwest to northeast of patterns of extreme precipitation and river discharge, concentrated in the northeast, southeast and Gulf regions, respectively (Knighton et al., 2019).

Regarding the comparison of our results with previous studies, Wahl et al. (2015) found that in New York City and Boston, the SLP and wind composites of those CEs defined by extreme storm surges and heavy precipitation differ from weather patterns associated with events with high storm surge and low precipitation. In this study, the WTs associated with the highest occurrence of CEs in the area of New York City and Boston (WT45 and WT46 in Figure 6) are characterized by a dipole of SLP, with a similar spatial structure as identified in Wahl et al. (2015). The main WTs associated with CE occurrence are 23, 30 and 37 which can be considered "subpatterns," following the description in Roller et al., 2016, of a more general weather regime pattern characterized by a large trough between the Midwest and 
East Coast, with a ridge to the west which generates the highest amount of precipitation in the eastern United States. WT29 and WT49 can be associated with another weather regime which exhibits a ridge over the south-eastern United States and a trough offshore, accompanied with south-west winds which bring precipitation into the farther southern United States (Roller et al., 2016).

On the other hand, CEs on the west coast of the United Kingdom are mainly associated with weather patterns that are principally characterized by dipole pressure fields resembling the positive phase of NAO (WT4, WT5), or low-pressure systems located close to the United Kingdom (WT6, WT14). These WTs resemble coastal-risk patterns derived along the west coast of the United Kingdom (20, 26, 29 and 30) by relating a weather pattern classification (Neal et al., 2016) to observed skew surges (Neal et al., 2018), which were also identified as the wettest synoptic types along the west coast of the United Kingdom (Richardson et al., 2018). Concurrent precipitation and wind extreme events at the western Iberian Peninsula also observed to be clearly associated with a cyclonic feature and that most of these cyclones $(60 \%)$ either cross the Iberian Peninsula or pass to the northwest (Hénin et al., 2021). A similar behaviour is observed in the spatial distribution of CEs associated with WT8, WT7 and WT6, and in the transition from WT8 to WT7 and WT6 from the analysis of the probability matrix.

The identification of the atmospheric patterns that are more (or less) likely to generate CEs can provide support to other applications that rely on meteorological processes, such as flood forecasting and warning systems. Outputs from predictions systems can be assigned to the closest matching predefined weather patterns to provide the likelihood of CEs which is associated with the occurrence of specific weather types. Furthermore, this weather-typing approach can also be used as a statistical downscaling method to obtain indirect long-term projections or long-term climate variability of compound flooding potential occurrence. Probabilities of weather patterns can be calculated in other time periods because synoptic variables (such as SLP) or mesoscale variables (such as precipitation) are often available for longer historical time periods (e.g., 20CR, new updates of ERA5) or climate projections (e.g., new CMIP6). Combining the WT probabilities and probabilities of getting a CE when a certain WT occurs (see Figure S6) allows estimation of the changes in the occurrence of coastal CEs in the past and on into the future.

Some subjectivity exists concerning selecting the optimal number of WTs. The purpose of these classifications is not to define weather regimes (e.g., Roller et al., 2016; Knighton et al., 2019), which usually requires a substantially reduced number of patterns (e.g., in the order of five or six). In our case, we need more patterns to differentiate between similar extratropical storms but with slight differences in the location of the centre of low-pressure systems and evolution which determine the area where CEs occurs. We have analysed several indicators related to the link between WTs and CEs and that inform about the performance of the WT classification in the characterization of CEs. These indicators are: the number of WTs that has associated CEs, the number of CEs within each WT and the probability of CEs when each WT occur (see Figure S9). We have selected $8 \times 8$ WTs for European coastlines and $7 \times 7$ WTs for U.S. coastlines because these sizes provide an equilibrium between indicators (we limit the number of WTs linked to CEs keeping similar occurrence of CEs associated with each WT as with lower number of WTs and a probability that a CE occurs within each WT close to higher number of WTs). In the case of U.S. coastlines, lower number of WTs is required because the analysis is only focused on extratropical season. In the WT classification for European sites, there are several WTs that only occur in summer (see Figure 3) and they do not have any CE associated which means that pattern's link to CEs are limited to similar number of WTs than for the U.S. coastlines.

While we identify compound flooding events from flood elevation due to the interaction of discharge and storm surge drivers, some processes remain unresolved. GTSM does not account for nonlinear surge-tide interactions, or interannual variability in mean sea levels due to steric effects or waves, reservoirs are not included in CaMa-Flood, and local variations in bathymetry are not accounted for in both models (Eilander et al., 2020). Although back-water level due to tidal and surge affecting river discharge (Moftakhari et al., 2017; Ganguli and Merz, 2019) is simulated in the water surface elevation, the river discharge can also affect the coastal water level (Piecuch et al., 2018). A two-way coupling between GTSM and CaMa-Flood could assess the complete interactions while the complex hydrodynamic interactions between different flood drivers in coastal areas could be solved using higher resolution 2D flood models (Eilander et al., 2020).

\section{8 | CONCLUSIONS}

In this paper, we have characterized the daily synoptic weather patterns associated with coastal compound events along the European and U.S. coastlines of the North Atlantic Ocean. First, we have identified compound events based on a proxy of the potential flooding impact defined by the water surface elevation at the 
estuarine mouths (linked to a catchment area larger than $1,000 \mathrm{~km}^{2}$ using the data provided by Eilander et al., 2020), driven by both extreme skew surge and river discharge. Second, weather patterns were obtained from a classification of sea level pressure fields and precipitation fields using k-means algorithm. The study area has been divided into two subdomains: (a) European and (b) U.S. coastlines due to climate differences regarding storm tracks of the extratropical cyclones and spatial patterns of precipitation. Moreover, only the extratropical season has been analysed here for the U.S. subdomain, because tropical cyclones are not well reproduced in ERA-Interim.

We have found that coastal compound events occurred more frequently along European as opposed to U.S. coastlines. Regarding the total number of compound events, areas with the highest occurrence of these events are concentrated in the northwest coast of the Iberian Peninsula, around Strait of Gibraltar and west coast of United Kingdom. In the case of U.S. locations, the areas with highest number of compound events are located mainly in the Gulf of Mexico and along the mid-eastern U.S. coastlines.

The weather-typing approach we have applied has allowed us to identify that the occurrence of compound events in each location is associated with few dominant weather patterns usually characterized by low-pressure systems accompanied with a spatial distribution of the precipitation concentrated over the surrounded area of the site. This is the reason why the occurrence of compound events along the European coastlines are concentrated in the main pathways of the cyclone storms that cross the North Atlantic Ocean conditioning the spatial distribution to the locations of the low-pressure systems. In the case of U.S. coastlines, locations along the Gulf of Mexico and south-middle eastern U.S. coastlines share the same weather types associated to compound events which represent storms that travel northward parallel to the coastline.

The approach we propose in this study allows to indirectly estimate probabilistic historical or future changes of the occurrence of coastal compound events based on the probability of WTs during those time periods. Besides, this analysis provides support to flood forecasting. Predicting if flooding impact is likelihood to be caused by a compound event can assist to prepare a better co-ordinated emergency plan which would increase the evacuation effectiveness and impact mitigation. Splitting the occurrence of compound events in the corresponding WTs discriminates the interannual variability based on the relationship with dominant climate indices in the North Atlantic Ocean.

\section{ACKNOWLEDGEMENTS}

This research forms part of the CHANCE project, which is supported by awards from the UK Natural Environment Research Council (NE/S010262/1) and US National Science Foundation (1929382). We would like to thank Dirk Eilander for providing support about the use of dataset of simulated water levels and discharge at river mouth locations globally which is available on Zenodo (doi: 10.5281/zenodo.3665734).

\section{AUTHOR CONTRIBUTIONS}

Paula Camus: Conceptualization; data curation; formal analysis; investigation; methodology; software; validation; visualization; writing - original draft. Ivan D. Haigh: Conceptualization; formal analysis; methodology; project administration; supervision; writing - review and editing. Thomas Wahl: Conceptualization; formal analysis; methodology; writing - review and editing. Ahmed A. Nasr: Conceptualization; formal analysis; writing - review and editing. Fernando J. Mendez: Formal analysis; methodology; writing - review and editing. Stephen Darby: Formal analysis; writing - review and editing. Robert J. Nicholls: Conceptualization; formal analysis; writing - review and editing.

\section{ORCID}

Paula Camus (1) https://orcid.org/0000-0002-8957-307X

\section{REFERENCES}

Anderson, D., Rueda, A., Cagigal, L., Antolinez, J.A.A., Mendez, F. J. and Ruggiero, P. (2019) Time-varying emulator for short and long-term analysis of coastal flood Hazard potential. Journal of Geophysical Research: Oceans, 124(12), 9209-9234.

Barnston, A.G. and Livezey, R.E. (1987) Classification, seasonality and persistence of low-frequency atmospheric circulation patterns. Monthly Weather Review, 115(6), 1083-1126. https://doi. org/10.1175/1520-0493.

Barry, R.G. and Chorley, R.J. (2003) Atmosphere, Weather and Climate. London and New York, NY: Routledge, $421 \mathrm{pp}$.

Beck, H.E., Van Dijk, A.I.J.M., Levizzani, V., Schellekens, J., Miralles, D.G., Martens, B. and De Roo, A.P.J. (2017) MSWEP: 3-hourly 0.25 deg; global gridded precipitation (1979-2015) by merging gauge, satellite, and reanalysis data. Hydrology and Earth System Sciences, 21, 589-615.

Bevacqua, E., Maraun, D., Vousdoukas, M.I., Voukouvalas, E., Vrac, M., Mentaschi, L. and Widmann, M. (2019) Higher probability of compound flooding from precipitation and storm surge in Europe under anthropogenic climate change. Science Advances, 5(9), eaaw5531.

Bevacqua, E., Vousdoukas, M.I., Shepherd, T.G. and Vrac, M. (2020) Brief communication: the role of using precipitation or river discharge data when assessing global coastal compound flooding. Natural Hazards and Earth System Sciences, 20(6), 1765-1782.

Cagigal, L., Rueda, A., Anderson, D., Ruggiero, P., Merrifield, M.A., Montaño, J., Coco, G. and Méndez, F.J. (2020) A multivariate, 
stochastic, climate-based wave emulator for shoreline change modelling. Ocean Modelling, 154, 101695.

Camus, P., Haigh, I.D., Nasr, A.A., Wahl, T., Darby, S.E. and Nicholls, R.J. (2021) Regional analysis of multivariate compound coastal flooding potential around Europe and environs: sensitivity analysis and spatial patterns. Natural Hazards Earth Systems. Science Discussion., 21, 2021-2040. https://doi.org/10. 5194/nhess-2021-50.

Camus, P., Losada, I.J., Izaguirre, C., Espejo, A., Menéndez, M. and Pérez, J. (2017) Statistical wave climate projections for coastal impact assessments. Earth's Future, 5(9), 918-933.

Camus, P., Menéndez, M., Méndez, F.J., Izaguirre, C., Espejo, A., Cánovas, V., Pérez, J., Rueda, A., Losada, I.J. and Medina, R. (2014) A weather-type statistical downscaling framework for ocean wave climate. Journal of Geophysical Research: Oceans, 119(11), 7389-7405.

Trenberth, K.E. and Caron, J.M. (2000) The southern oscillation revisited: sea-level pressures, surface temperatures, and precipitation. Journal of Climate, 13, 4358-4365.

Carrère, L., Lyard, F., Cancet, M., Guillot, A. and Roblou, L. (2013) A new global tidal model taking advantage of nearly 20 years of altimetry. In: Ouwehand, L. (Ed.) 20 Years of Progress in Radar Altimatry, held 24-29 September, 2012 in Venice, Italy.

Castelle, B., Dodet, G., Masselink, G. and Scott, T. (2017) A new climate index controlling winter wave activity along the Atlantic coast of Europe: the west Europe pressure anomaly. Geophysical Research Letters, 44(3), 1384-1392. https://doi.org/10.1002/ 2016 gl072379.

Hewitson, B.C. and Crane, R.G. (2002) Self-organizing maps: applications to synoptic climatology. Climate Research, 22(1), 13-26.

Colucci, S.J. (1976) Winter cyclone frequencies over the eastern United States and adjacent western Atlantic, 1964-1973. Bulletin of the American Meteorological Society, 57, 548-553.

Couasnon, A., Eilander, D., Muis, S., Veldkamp, T.I.E., Haigh, I.D., Wahl, T., Winsemius, H.C. and Ward, P.J. (2020) Measuring compound flood potential from river discharge and storm surge extremes at the global scale. Natural Hazards and Earth System Sciences, 20(2), 489-504.

De Luca, P., Messori, G., Pons, F.M.E. and Faranda, D. (2020) Dynamical systems theory sheds new light on compound climate extremes in Europe and eastern North America. Quarterly Journal of the Royal Meteorological Society, 146(729), 16361650.

Dee, D.P., Uppala, S.M., Simmons, A.J., Berrisford, P., Poli, P., Kobayashi, S., Andrae, U., Balmaseda, M.A., Balsamo, G., Bauer, P., Bechtold, P., Beljaars, A.C.M., van de Berg, L., Bidlot, J., Bormann, N., Delsol, C., Dragani, R., Fuentes, M., Geer, A.J., Haimberger, L., Healy, S.B., Hersbach, H., Hólm, E. V., Isaksen, L., Kållberg, P., Köhler, M., Matricardi, M., McNally, A.P., Monge-Sanz, B.M., Morcrette, J.-J., Park, B.-K., Peubey, C., de Rosnay, P., Tavolato, C., Thépaut, J.-N. and Vitart, F. (2011) The ERA-Interim reanalysis: configuration and 11 performance of the data assimilation system. Quarterly Journal of the Royal Meteorological Society, 137, 553-597.

Eilander, D., Couasnon, A., Ikeuchi, H., Muis, S., Yamazaki, D., Winsemius, H.C. and Ward, P.J. (2020) The effect of surge on riverine flood hazard and impact in deltas globally. Environmental Research Letters, 15(10), 104007. https://doi.org/10. 1088/1748-9326/ab8ca6.
Ganguli, P. and Merz, B. (2019) Trends in compound flooding in northwestern Europe during 1901-2014. Geophysical Research Letters, 46(19), 10810-10820.

Ganguli, P., Paprotny, D., Hasan, M., Güntner, A. and Merz, B. (2020) Projected Changes in Compound Flood Hazard From Riverine and Coastal Floods in Northwestern Europe. Earth's Future, 8(11), e2020EF001752.

Gutiérrez, J.M., Cano, R., Cofiño, A.S. and Sordo, C. (2005) Analysis and downscaling multi-model seasonal forecasts in Peru using self-organizing maps. Tellus, Series A: Dynamic Meteorology and Oceanography, 57(3), 435-447.

Hendry, A., Haigh, I.D., Nicholls, R.J., Winter, H., Neal, R., Wahl, T., Joly-Laugel, A. and Darby, S.E. (2019) Assessing the characteristics and drivers of compound flooding events around the UK coast. Hydrology and Earth System Sciences, 23(7), 3117-3139. https://doi.org/10.5194/hess-23-3117-2019.

Hénin, R., Ramos, A.M., Pinto, J.G. and Liberato, M.L.R. (2021) A ranking of concurrent precipitation and wind events for the Iberian Peninsula. International Journal of Climatology, 41(2), 1421-1437.

Hersbach, H., Bell, B., Berrisford, P., Hirahara, S., Horányi, A., Muñoz-Sabater, J., Nicolas, J., Peubey, C., Radu, R., Schepers, D., Simmons, A., Soci, C., Abdalla, S., Abellan, X., Balsamo, G., Bechtold, P., Biavati, G., Bidlot, J., Bonavita, M., De Chiara, G., Dahlgren, P., Dee, D., Diamantakis, M., Dragani, R., Flemming, J., Forbes, R., Fuentes, M., Geer, A., Haimberger, L., Healy, S., Hogan, R.J., Hólm, E., Janisková, M., Keeley, S., Laloyaux, P., Lopez, P., Lupu, C., Radnoti, G., de Rosnay, P., Rozum, I., Vamborg, F., Villaume, S. and Thépaut, J.-N. (2020) The ERA5 global reanalysis. Quarterly Journal of the Royal Meteorological Society, 146(730), 1999-2049.

Hess, P. and Brezowky, H. (1969) Katalog der Grosswetterlagen Europas, 2. neubearbeitete und erg̈anzte Aufl. In: Berichte des Deutschen Wetterdienstes, Vol. 113, 15th edition. Offenbach am Main: Deutscher Wetterdienst.

Hirsch, M.E., DeGaetano, A.T. and Colucci, S.J. (2001) An East Coast winter storm climatology. Journal of Climate, 14, 882-899.

Huth, R., Beck, C., Philipp, A., Demuzere, M., Ustrnul, Z., Cahynová, M., Kyselý, J. and Tveito, O.E. (2008) Classifications of atmospheric circulation patterns: recent advances and applications. Annals of the New York Academy of Sciences, 1146, 105-152.

Knighton, J., Pleiss, G., Carter, E., Lyon, S., Walter, M.T. and Steinschneider, S. (2019) Potential predictability of regional precipitation and discharge extremes using synoptic-scale climate information via machine learning: an evaluation for the eastern Continental United States. Journal of Hydrometeorology, 20(5), 883-900.

Kunkel, K.E. and Angel, J.R. (1999) Relationship of ENSO to snowfall and related cyclone activity in the contiguous United States. Journal of Geophysical Research, 104(D16), 19425-19434.

Lamb, H.H. (1972) British Isles weather types and a register of daily sequence of circulation patterns, 1861-1971. In: Geophysical Memoir, Vol. 116. London: HMSO.

Messmer, M. and Simmonds, I. (2021) Global analysis of cycloneinduced compound precipitation and wind extreme events. Weather and Climate Extremes, 32, 100324. https://doi.org/10. 1016/j.wace.2021.100324. 
Moftakhari, H.R., Salvadori, G., AghaKouchak, A., Sanders, B.F. and Matthew, R.A. (2017) Compounding effects of sea level rise and fluvial flooding. Proceedings of the National Academy of Sciences of the United States of America, 114(37), 9785-9790.

Muis, S., Verlaan, M., Winsemius, H.C., Aerts, J.C.J.H. and Ward, P.J. (2016) A global reanalysis of storm surges and extreme sea levels. Nature Communications, 7, 11969.

Nasr, A.A., Wahl, T., Rashid, M.M., Camus, P. and Haigh, I.D. (2021) Assessing the dependence structure between oceanographic, fluvial, and pluvial flooding drivers along the United States coastline. Hydrology and Earth System Sciences, Discussion, 25, 6203-6222. https://doi.org/10.5194/hess2021-268.

Neal, R., Dankers, R., Saulter, A., Lane, A., Millard, J., Robbins, G. and Price, D. (2018) Use of probabilistic medium- to long-range weather-pattern forecasts for identifying periods with an increased likelihood of coastal flooding around the UK. Meteorological Applications, 25(4), 534-547.

Neal, R., Fereday, D., Crocker, R. and Comer, R.E. (2016) A flexible approach to defining weather patterns and their application in weather forecasting over Europe. Meteorological Applications, 23(3), 389-400. https://doi.org/10.1002/met.1563.

Notaro, M., Wang, W.-C. and Gong, W. (2006) Model and observational analysis of the northeast U.S. regional climate and its relationship to the PNA and NAO patterns during earlywinter. Monthly Weather Review, 134, 3479-3505. https://doi.org/10. 1175/MWR3234.1.

Paprotny, D., Morales-Nápoles, O. and Jonkman, S.N. (2018) HANZE: a pan-European database of exposure to natural hazards and damaging historical floods since 1870. Earth System Science Data, 10, 565581. https://doi.org/10.5194/essd-10-565-2018.

Piecuch, C.G., Bittermann, K., Kemp, A.C., Ponte, R.M., Little, C. M., Engelhart, S.E. and Lentz, S.J. (2018) River-discharge effects on United States Atlantic and Gulf coast sea-level changes. Proceedings of the National Academy of Sciences of the United States of America, 115(30), 7729-7734.

Richardson, D., Fowler, H.J., Kilsby, C.G. and Neal, R. (2018) A new precipitation and drought climatology based on weather patterns. International Journal of Climatology, 38(2), 630-648.

Roller, C.D., Qian, J.-H., Agel, L., Barlow, M. and Moron, V. (2016) Winter weather regimes in the Northeast United States. Journal of Climate, 29, 2963-2980. https://doi.org/10.1175/JCLI-D-15-0274.1.

Rueda, A., Camus, P., Tomás, A., Vitousek, S. and Méndez, F.J. (2016) A multivariate extreme wave and storm surge climate emulator based on weather patterns. Ocean Modelling, 104, 242-251. https://doi.org/10.1016/j.ocemod.2016.06.008.

Ruffault, J., Moron, V., Trigo, R.M. and Curt, T. (2017) Daily synoptic conditions associated with large fire occurrence in Mediterranean France: evidence for a wind-driven fire regime. International Journal of Climatology, 37(1), 524-533.

Ruocco, A.C., Nicholls, R.J., Haigh, I.D. and Wadey, M.P. (2011) Reconstructing coastal flood occurrence combining sea level and media sources: a case study of the Solent, UK since 1935. Natural Hazards, 59(3), 1773-1796. https://doi.org/10.1007/ s11069-011-9868-7.

Schauer, A.R., Hendrikx, J., Birkeland, K.W. and Mock, C.J. (2021) Synoptic atmospheric circulation patterns associated with deep persistent slab avalanches in the western United States. Natural
Hazards and Earth System Sciences, 21, 757-774. https://doi. org/10.5194/nhess-21-757-2021.

Sheridan, S.C. (2002) The redevelopment of a weather-type classification scheme for North America. International Journal of Climatology, 22(1), 51-68.

Sheridan, S.C. and Lee, C.C. (2011) The self-organizing map in synoptic climatological research. Progress in Physical Geography: Earth and Environment, 35(1), 109-119. https://doi.org/10.1177/ 0309133310397582.

Valle-Levinson, A., Olabarrieta, M. and Heilman, L. (2020) Compound flooding in Houston-Galveston Bay during Hurricane Harvey. Science of the Total Environment, 747, 141272. https:// doi.org/10.1016/j.scitotenv.2020.141272.

Wahl, T., Jain, S., Bender, J., Meyers, S.D. and Luther, M.E. (2015) Increasing risk of compound flooding from storm surge and rainfall for major US cities. Nature Climate Change, 5(12), 1093-1097. https://doi.org/10.1038/nclimate2736.

Ward, P.J., Couasnon, A., Eilander, D., Haigh, I.D., Hendry, A., Muis, S., Veldkamp, T.I.E., Winsemius, H.C. and Wahl, T. (2018) Dependence between high sea-level and high river discharge increases flood hazard in global deltas and estuaries. Environmental Research Letters, 13(8), 084012. https://doi.org/10.1088/17489326/aad400

Wu, W., McInnes, K., O'Grady, J., Hoeke, R., Leonard, M. and Westra, S. (2018) Mapping dependence between extreme rainfall and storm surge. Journal of Geophysical Research: Ocean, 123(4), 2461-2474. https://doi.org/10.1002/2017JC013472.

Yamazaki, D., Kanae, S., Kim, H. and Oki, T. (2011) A physically based description of floodplain inundation 24 dynamics in a global river routing model. Water Resources Research, 47, 1-21.

Yarnal, B. (1993) Synoptic Climatology in Environmental Analysis. London: Belhaven Press, 195 pp.

Zscheischler, J., Martius, O., Westra, S., Bevacqua, E., Raymond, C., Horton, R.M., van den Hurk, B., AghaKouchak, A., Jézéquel, A., Mahecha, M.D., Maraun, D., Ramos, A.M., Ridder, N.N., Thiery, W. and Vignotto, E. (2020) A typology of compound weather and climate events. Nature Reviews Earth and Environment, 1, 333-347. https://doi.org/10.1038/s43017-020-0060-z.

Zscheischler, J., Westra, S., van den Hurk, B.J.J.M., Seneviratne, S. I., Ward, P.J., Pitman, A., AghaKouchak, A., Bresch, D.N., Leonard, M., Wahl, T. and Zhang, X. (2018) Future climate risk from compound events. Nature Climate Change, 8, 469-477. https://doi.org/10.1038/s41558-018-0156-3.

\section{SUPPORTING INFORMATION}

Additional supporting information may be found in the online version of the article at the publisher's website.

How to cite this article: Camus, P., Haigh, I. D., Wahl, T., Nasr, A. A., Méndez, F. J., Darby, S. E., \& Nicholls, R. J. (2022). Daily synoptic conditions associated with occurrences of compound events in estuaries along North Atlantic coastlines. International Journal of Climatology, 1-20. https:// doi.org/10.1002/joc.7556 